\title{
American Association for Thoracic Surgery/International Society for Heart and Lung Transplantation guidelines on selected topics in mechanical circulatory support
}

\author{
Editors: \\ Contributing \\ Authors:
}

Reviewers:

\author{
James K. Kirklin, ${ }^{\text {a }}$ Francis D. Pagani, ${ }^{\mathrm{b}}$ Daniel J. Goldstein, ${ }^{\mathrm{c}}$ Ranjit John, ${ }^{\mathrm{d}}$ and \\ Joseph G. Rogers ${ }^{\mathrm{e}}$
}

Pavan Atluri, ${ }^{\mathrm{f}}$ Francisco A. Arabia, ${ }^{\mathrm{g}}$ Anson Cheung, ${ }^{\mathrm{h}}$ William Holman, ${ }^{\mathrm{a}}$ Charles Hoopes, ${ }^{\mathrm{a}}$ Valuvan Jeevanandam, ${ }^{\mathrm{i}}$ Ranjit John, ${ }^{\mathrm{d}}$ Ulrich P. Jorde, ${ }^{\mathrm{c}}$ Carmelo A. Milano, Nader Moazami, ${ }^{j}$ Yoshifumi Naka, ${ }^{\mathrm{k}}$ Ivan Netuka, ${ }^{\mathrm{l}}$ Francis D. Pagani, ${ }^{\mathrm{b}}$ Salpy V. Pamboukian, ${ }^{a}$ Sean Pinney, ${ }^{\mathrm{m}}$ Joseph G. Rogers, ${ }^{\mathrm{e}}$ Craig H. Selzman, ${ }^{\mathrm{n}}$ Scott Silverstry, ${ }^{\mathrm{o}}$ Mark Slaughter, ${ }^{\mathrm{p}}$ John Stulak, ${ }^{\mathrm{q}}$ Jeff Teuteberg, ${ }^{\mathrm{r}}$ and Juliane Vierecke

\section{TABLE OF CONTENTS}

Preoperative Evaulation and Optimization . . . . . . . . . . . . . . . . . 666

Preimplant Cardiac Evaluation . . . . . . . . . . . . 866

Hemodynamic parameters. . . . . . . . . . . . . . . . . . . . . . . .

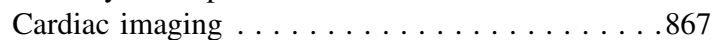

RV function . . . . . . . . . . . . . . . . . . . . . . . . . . . . . . . . . . . . . . . . . .

Coronary angiogram . . . . . . . . . . . . . . . . . . . . . . . . . . . . .

Cardiac dysrhythmias. . . . . . . . . . . . . . . . . . . . . . . . . . . . . . . . . . . . .

Functional studies . . . . . . . . . . . . . . . . . . . . . . . . . . . . . . . . . . .

Evaluation of Noncardiac Organ Systems. . . . . . . . . . . . . . . . . . . . . . 867

Renal function. . . . . . . . . . . . . . . . . . . . . . . . . . . . . . . . . . . . . .

Gastrointestinal system. . . . . . . . . . . . . . . . . . . . . . . . . . . . . . . . . . . .

Hepatic function . . . . . . . . . . . . . . . . . . . . . . . . . . . . . . . . . . .

Hematology and Coagulation . . . . . . . . . . . . . . . . . . . . . 868

Peripheral Vascular Disease . . . . . . . . . . . . . . . . . . . . . . . . . . . . . . . .

Pulmonary function . . . . . . . . . . . . . . . . . . . . . . . . . . . . . . . . . . . . .

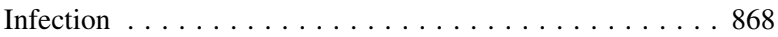

Nutrition/Body Mass Index. . . . . . . . . . . . . . . . . . 869

Neurological/Neurocognitive Evaluation. . . . . . . . . . . . 869

Psychosocial. . . . . . . . . . . . . . . . . . . . . . . 869

Hemodynamic Parameter Optimization . . . . . . . . . . . . . . . . . 869

Treating volume overload . . . . . . . . . . . . . . 869

Inotropic support . . . . . . . . . . . . . . . . . . . . . . . . . . . . . . . . . . . . . .

Management of PVR . . . . . . . . . . . . . . .869

\footnotetext{
From the a Department of Surgery, University of Alabama at Birmingham, Birmingham, Ala; ${ }^{\mathrm{b}}$ University of Michigan, Ann Arbor, Mich; ${ }^{\mathrm{c}}$ Montefiore Medical Center/Albert Einstein College of Medicine, Bronx, NY; ${ }^{\mathrm{d}}$ University of Minnesota, Minneapolis, Minn; ${ }^{\mathrm{e}}$ Duke University School of Medicine, Durham, NC; ${ }^{\mathrm{f}}$ University of Pennsylvania, Philadelphia, Pa; ${ }^{\mathrm{g} B a n n e r}$ Health University of Arizona Medical Center, Phoenix, Ariz; ${ }^{\text {h}}$ University of British Columbia, Vancouver, British Columbia, Canada, ${ }^{\mathrm{i}}$ University of Chicago, Chicago, Ill; ${ }^{\mathrm{j}}$ Langone Medical Center, New York University, New York, NY; ${ }^{k}$ Columbia University College of Physicians \& Surgeons, New York, NY; Institute for Clinical and Experimental Medicine, Prague, Czech Republic; ${ }^{\mathrm{m}}$ Mount Sinai Hospital, New York, NY; ${ }^{\mathrm{n}} \mathrm{U}-$ niversity of Utah School of Medicine, Salt Lake City, Utah; ${ }^{\circ}$ Florida Hospital Transplant Institute, Orlando, Fla; ${ }^{\mathrm{p}}$ University of Louisville, Ky; ${ }^{\mathrm{q}}$ Mayo Clinic College of Medicine and Science, Rochester, Minn; 'Stanford University, Stanford, Calif; ' University of Cincinnati College of Medicine, Cincinnati, Ohio;
}

Support Techniques in Cardiogenic Shock . . . . . . . . . . 870 Intra-Aortic Balloon Pump Support . . . . . . . . . . . . . . 870 Percutaneous/Peripheral Access Assist Devices. . . . . . . . 870 Left atrium to aorta and LV to aorta percutaneous technologies . . . . . . . . . . . . . . . . . . . . . . . . . . . . . .

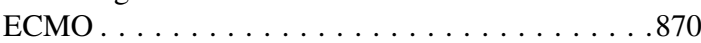

Right-sided support . . . . . . . . . . . . . . . . . . . . . . . . . . . . . . . .

Biventricular Support . . . . . . . . . . . . . . . . . . . . . . . . . . 871

Biventricular Failure: Etiologies . . . . . . . . . . . 871

BVF: Incidence. . . . . . . . . . . . . . . . . . . . . 872

Indications for Biventricular Support . . . . . . . . . . . 872

Methods of RV Support. . . . . . . . . . . . . . . 872

Surgical Approach . . . . . . . . . . . . . . . . . . . . . . .

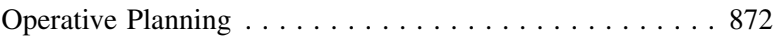

Decision Making. . . . . . . . . . . . . . . . . . . . . . . . . . . . 872

Median Sternotomy . . . . . . . . . . . . . . . . . . . . . . . . . . . 873

Alternative Approaches . . . . . . . . . . . . . . . . . . . . . . . . 873

Management of Postoperative Bleeding . . . . . . . . . . . . . . . . . . . . . . . . . . . . .

Anticoagulation Management . . . . . . . . . . . . . . . . . . . . . . . . . . . . . . .

Optimizing Pump Speed . . . . . . . . . . . . . . . . . . . . . . . . . . . . . . . .

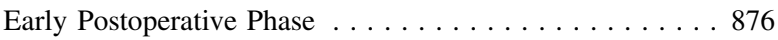

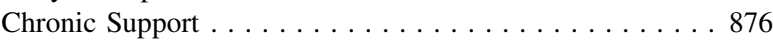
Aortic insufficiency . . . . . . . . . . 876

'Department for Cardiothoracic Surgery, Newcastle upon Tyne Freeman Hospital, Newcastle upon Tyne, United Kingdom; "Department of Cardiothoracic Surgery, Massachusetts General Hospital, Boston, Mass.

This article has been copublished in The Journal of Thoracic and Cardiovascular Surgery and the Journal of Heart and Lung Transplantation.

Address for reprints: James K. Kirklin, MD, Department of Surgery, The University of Alabama at Birmingham, ZRB 721, 1900 University Blvd, Birmingham, AL 35294 (E-mail: jkirklin@uabmc.edu).

J Thorac Cardiovasc Surg 2020;159:865-96 $0022-5223 / \$ 36.00$

Copyright $\Subset 2019$ by The American Association for Thoracic Surgery, International Society for Heart and Lung Transplantation. Published by Elsevier Inc.

https://doi.org/10.1016/j.jtcvs.2019.12.021 
Right heart failure . . . . . . . . . . . . . . 876

Bleeding diathesis . . . . . . . . . . . . . . . . . .

Device-Specific Performance Characteristics and

Implications for Pump Speed Adjustment. . . . . . . . . 876

Diagnosis and Management of Pump Malfunction . . . . . 8876

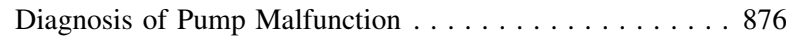

Interrogation of the VAD Controller . . . . . . . . . . 877

LDH . . . . . . . . . . . . . . . . . . . . . . . . . 877

Plasma Free Hemoglobin . . . . . . . . . . . . . . . . 878

Other Laboratory Parameters . . . . . . . . . . . . . . . . . . . . . . . . 878

Cardiac Imaging . . . . . . . . . . . . . . . . . . . . . 878

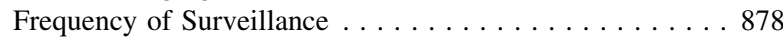

Pump Thrombosis . . . . . . . . . . . . . . . . . . 878

Medical Management . . . . . . . . . . . . . . . . . . . . 879

Surgical Pump Exchange . . . . . . . . . . . . . . . . . . . . 879

Mechanical Device Failures . . . . . . . . . . . . . . 880

Management of Pump-Related Infections. . . . . . . . . . . . . . . . . . . . . . . .

Driveline Infection . . . . . . . . . . . . . . . . . . 881

Mediastinal VAD-Related Infections . . . . . . . . . . 882

Management of the Infected VAD at Transplant . . . . . . . 882

Strategies to Promote Myocardial Recovery . . . . . . . . . . 883

Patient Selection . . . . . . . . . . . . . . . . . 883

Adjuvant Therapies . . . . . . . . . . . . . . . . . . 883

Surgical Approaches . . . . . . . . . . . . . . . 888

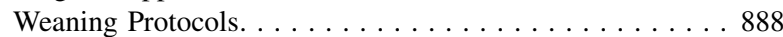

Limitations. . . . . . . . . . . . . . . . . . . . . . . . . . 8889

Conflict of Interest Statement . . . . . . . . . . . . . . . . . . . . . . . . . . . . . . . . . . . . . . . . . .

References . . . . . . . . . . . . . . . . . . . . . . . . . . 889

Appendix 1. Relationships With Industry and Other Relevant

Entities for Guideline Editors, Contributing Authors, and

Reviewers. . . . . . . . . . . . . . . . . . . . . .895

Mechanical circulatory support (MCS) evolved from an engineering dream to clinical reality during the 1980s when increasing numbers of patients were dying on heart transplant wait lists. Following the Randomized Evaluation of Mechanical Assistance for the Treatment of Congestive Heart Failure Trial, ${ }^{1}$ the US Food and Drug Administration (FDA) approved a pulsatile implantable left ventricular assist device (LVAD) for long-term implantation in 2002. When the FDA approved the first US continuous flow (CF) LVAD in 2008, the landscape had changed dramatically. With demonstrated survival on device exceeding $80 \%$ at 1 year, ${ }^{2}$ implants in the United States progressively increased to nearly 3000 per year. With the maturation of this field, guidelines for patient care and decision making have become more evidenced-based. This consensus guidelines document focuses on selected topics in patient management. The writing group included 25 surgeons and 10 heart failure cardiologists. After review and evaluation of available literature and incorporation of their collective experience, specific recommendations were assigned a class and level of evidence (Table 1).,

\section{PREOPERATIVE EVAULATION AND OPTIMIZATION}

The preoperative evaluation of a patient considered for implantation of a durable LVAD begins with assessment of the criteria that define the indication for implant (eg, bridge to transplant [BTT], bridge to candidacy, or destination therapy [DT]). Patients believed to be candidates for LVAD support commonly present with significant concomitant medical conditions, many of which are direct sequelae of the heart failure syndrome.

Several assessment tools characterize the degree of illness in patients with heart failure to optimally time LVAD implantation, including the Seattle Heart failure Model $^{5}$ and the Heart Failure Survival Score. ${ }^{6}$ Furthermore, the Interagency Registry for Mechanically Assisted Circulatory Support (INTERMACS) has established patient profiles that also stratify early risk, expected hospital length of stay, and late survival. ${ }^{7}$ Numerous INTERMACS analyses support the practice of stabilizing high-risk patients before LVAD implantation and intervening before irreversible end organ damage. Multivariable risk scores predict operative risk based on preoperative clinical status, ${ }^{8,9}$ but the accuracy of these scores at the patient level is limited. Although individual organ system dysfunction may be an absolute contraindication for VAD surgery, a decision to implant will often involve a cumulative assessment of several relative contraindications and the associated overall risk.

\section{Preimplant Cardiac Evaluation}

Hemodynamic parameters. Unless contraindicated by clinical condition, right heart catheterization should be

TABLE 1. American Association for Thoracic Surgery/International Society for Heart and Lung Transplantation guidelines grading criteria $^{3,4}$

\begin{tabular}{lc}
\hline Class I & $\begin{array}{c}\text { Evidence and/or general agreement that a } \\
\text { given treatment or procedure is beneficial, } \\
\text { useful, and effective } \\
\text { Conflicting evidence and/or divergence of } \\
\text { opinion about the usefulness/efficacy of } \\
\text { the treatment or procedure } \\
\text { Weight of evidence/opinion is in favor of } \\
\text { usefulness/efficacy }\end{array}$ \\
\hline Class IIa & $\begin{array}{c}\text { Usefulness/efficacy is less well established } \\
\text { by evidence/opinion }\end{array}$ \\
\hline Class IIb & $\begin{array}{c}\text { Evidence or general agreement that the } \\
\text { treatment or procedure is not useful or } \\
\text { effective and in some cases may be harmful } \\
\text { Data derived from multiple randomized } \\
\text { clinical trials or meta-analyses }\end{array}$ \\
\hline Level of Evidence A & $\begin{array}{c}\text { Data derived from a single randomized } \\
\text { clinical trial or large non-randomized } \\
\text { studies }\end{array}$ \\
\hline Level of Evidence B & $\begin{array}{l}\text { Consensus of opinion of the experts and/or } \\
\text { small studies, retrospective studies, } \\
\text { registries }\end{array}$ \\
\hline Level of Evidence C & \\
\hline
\end{tabular}


obtained in all patients to assess their filling pressures, pulmonary vascular resistance (PVR), transpulmonary gradient (TPG), and cardiac output. ${ }^{10}$ Persistently elevated left-sided filling pressure can lead to passive elevation of pulmonary arterial pressures. At times, either alone or in combination with other factors such as pre-existing pulmonary disease, it can lead to an elevated TPG and/or PVR, factors that have been correlated with the subsequent development of postimplant right heart failure.

Cardiac imaging. All patients being evaluated for MCS should have an assessment of right ventricular (RV) function and LV function, valvular dysfunction (particularly aortic insufficiency), and other structural abnormalities that may contribute to the heart failure status and may need to be addressed at the time of or complicate implantation of durable MCS. A transthoracic echocardiogram is the most accessible tool for this assessment.

RV function. RV failure is a major contributor to adverse outcomes and death following LVAD implant. Assessment of RV function includes physical exam, laboratory tests, echocardiography, and hemodynamic parameter measurements. Predictive models may inform the clinician about the likelihood of postoperative RV failure. ${ }^{11-17}$ Patients at risk should not be summarily excluded as candidates for LVAD therapy. Instead, preparation and prompt treatment for significant RV dysfunction should be undertaken. ${ }^{18,19}$

Coronary angiogram. A large cohort of the population eligible for mechanically assisted circulation will have concomitant coronary artery disease. Assessment of the coronary arteries is reasonable in patients with known coronary artery disease or in individuals at high risk to rule out the possibility of reversible causes of LV dysfunction. The unloading properties of an LVAD reduce myocardial oxygen demand and wall tension, making postimplant angina less common.

Cardiac dysrhythmias. Atrial dysrhythmias, particularly chronic atrial fibrillation, may increase the risk for thromboembolic events. An electrophysiologic evaluation may be advisable to ascertain the possibility of a preoperative ablation procedure or pharmacologic treatments. ${ }^{20}$ Consideration should be given to surgical management of the left atrial appendage in patients with atrial fibrillation at the time of LVAD implant.

The incidence of ventricular dysrhythmias after mechanical support is $34 \%$ to $53 \%$ depending on the series, method of detection, and duration of follow-up. Preimplant ventricular tachycardia is a common risk factor for postoperative ventricular dysrhythmias. ${ }^{20}$ Decompensated heart failure with elevated filling pressures may lead to or aggravate pre-existing ventricular dysrhythmias and hence may improve with hemodynamic optimization. Thus, all patients with decompensated hemodynamic parameters and recurrent ventricular dysrhythmias should have a trial of hemodynamic optimization in addition to antiarrhythmic therapy. Patients with persistent ventricular tachycardia, particularly with known coronary artery disease, should be screened for ischemia. In patients with high ventricular arrhythmia burden despite pharmacological therapy, consideration can be given to concomitant intraoperative mapping and ablation of ventricular tachycardia.

Given the influence of ventricular dysrhythmias on RV function after LV support, patients with persistent ventricular dysrhythmias despite adequate hemodynamic parameters and antiarrhythmic therapy and no evidence of acute ischemia should be considered at high risk for LV support alone.

Functional studies. In the context of evaluating patients for advanced heart failure therapies, most clinicians perform a functional study to clarify the extent of a patient's physical limitations. Perhaps the best-validated functional study is the cardiopulmonary stress test that provides patient-level risk stratification. In the setting of a maximal study (respiratory exchange ratio $>1.1$ ), peak oxygen consumption $<14 \mathrm{~mL} / \mathrm{kg} / \mathrm{min}$ (or $<50 \%$ of predicted, whichever is lowest), and/or a ventilation/carbon dioxide production slope $>36$ have been associated with marked impairment in cardiac reserve and poor short- to intermediate-term prognosis. Most US payors use these values as qualifying criteria for destination therapy LVAD implantation.

\section{Evaluation of Noncardiac Organ Systems}

Renal function. Renal dysfunction is a predictor of adverse outcomes after LVAD implantation. ${ }^{21-25}$ Although several measures of renal dysfunction are used clinically, estimated glomerular filtration rate provides effective risk stratification for subsequent renal failure and mortality following VAD implant. Consideration of chronic versus acute or acute on chronic renal dysfunction with potential reversal of dysfunction is vital to decision making because these are very different clinical manifestations with varying risk. ${ }^{25-30}$ For example, eGFR $>60$ is not associated with additional risk for morbidity or mortality; eGFR 30 to 60 will increase overall risk and should be considered in the overall risk stratification; and eGFR $<30$ should be considered a marker of high risk for adverse outcome following VAD implant.

In the case of acute renal dysfunction, eGFR $<30$ with the need for dialysis should be considered a marker of high risk for adverse outcome following VAD implant; and eGFR 30 to 60 will increase overall risk and should be considered in the overall risk stratification.

Patients with a history of prostate radiation with or without active hematuria should be approached with caution for LVAD implantation, as hemorrhagic cystitis can develop postimplant and greatly complicate their management.

Gastrointestinal system. Patients require systemic antithrombotic therapy following LVAD implant. Moreover, 
gastrointestinal (GI) bleeding is a major adverse event limiting the success of contemporary LVADs. ${ }^{31-33}$ Caution should be exercised before considering implantation of CF LVADs in patients with a history of significant GI bleeding, particularly those with known arteriovenous malformations. Discovery of microcytic anemia in the preoperative evaluation phase mandates a thorough investigation of the GI tract. A history of GI malignancy should prompt thorough evaluation of the GI tract and search for metastatic disease. Screening colonoscopy should be considered in all patients older than age 50 years. Hepatic function. Congestive hepatopathy and hepatic dysfunction may occur in patients with significant volume overload as a result of RV failure and/or severe tricuspid valve regurgitation. Because hepatic dysfunction is associated with worse outcomes after LVAD implant, ${ }^{34,35}$ preoperative screening with liver function tests, ultrasonography, or even biopsy, and measurement of portal pressures (if advanced cirrhosis is suspected) can be helpful to assess risk. Presence of cirrhosis contraindicates LVAD implantation.

Two subgroups of hepatic injury patterns exist and should be considered separately based upon etiology: chronic liver injury and acute liver injury. Assessment of liver function should begin with analysis of standard hepatic laboratory parameters (eg, total bilirubin, aspartate transaminase, and alanine aminotransferase) and synthetic parameters (eg, coagulation profile and albumin). With concerns of hepatic dysfunction, consideration should be given for hepatic imaging with subsequent biopsy and concomitant measurement of portal pressures.

For chronic liver injury, total bilirubin $>3.0 \mathrm{~g} / \mathrm{dL}$ should be considered a contraindication for VAD implant; cirrhosis should be considered a contraindication for VAD implant; a chronic model for end-stage liver disease score $>17$ should be considered a contraindication for VAD implant; total bilirubin $<1.0 \mathrm{~g} / \mathrm{dL}$ is not associated with increased risk; a hepatic biopsy with mild fibrosis is not associated with increased risk; and total bilirubin between 1.0 and $3.0 \mathrm{~g} / \mathrm{dL}$ will increase overall risk and should be considered in the overall risk stratification.

For acute liver dysfunction/injury, rising hepatic transaminase or total bilirubin levels are associated with increased risk for VAD implant until hepatic recovery is evident; total bilirubin $>3.0 \mathrm{~g} / \mathrm{dL}$ without improvement should be considered a relative contraindication for VAD implant; and total bilirubin $<3.0 \mathrm{~g} / \mathrm{dL}$ for at least 48 hours without normalized transaminase levels is associated with slightly increased risk for VAD implant.

\section{Hematology and Coagulation}

Anemia and thrombocytopenia should be evaluated before LVAD implantation. Similarly, abnormalities in coagulation parameters, most commonly prothrombin time (PT)/ international normalized ratio (INR), partial thromboplastin time (PTT), and presence of heparin-induced thrombocytopenia antibodies, should be evaluated before implant. Findings suggestive of a prothrombotic state argues against the use of contemporary LVADs in light of the propensity for thrombosis associated with these technologies. Newer available technologies may be more resilient to pump thrombosis and lessen the influence of a prothrombotic state.

\section{Peripheral Vascular Disease}

Peripheral vascular disease may be evaluated before LVAD implant with physical examination of peripheral pulses in upper and lower extremities, abdominal ultrasonography, and ankle-brachial index. Significant peripheral vascular disease was an exclusion criterion in many LVAD clinical trials. In patients with prior sternotomy, knowledge of the status of the femoral arteries is mandatory in the event that access be required for emergency institution of cardiopulmonary bypass; if they are heavily diseased, alternative arterial access should be considered; that is, axillary artery. Extensive atherosclerotic disease may preclude candidacy for LVAD support. ${ }^{36}$

Pulmonary function. Chronic lung disease can influence postoperative recovery resulting in prolonged ventilator dependence, residual dyspnea, impaired functional capacity, and increased morbidity and mortality following LVAD implant. Detailed analysis of pulmonary function based on history, physical examination, pulmonary function tests, and imaging should be performed. Preoperative consultation with a pulmonary medicine specialist should be considered for patients with well established moderateto-severe obstructive or restrictive disease. In this situation, accurate evaluation of pulmonary function can be challenging due to coexistence of advanced heart failure. In general, if pulmonary function testing documents forced expiratory volume in 1 second, forced vital capacity, and carbon monoxide diffusing capacity all $<50 \%$ of predicted, then candidacy for VAD therapy should be questioned. Chronic obstructive lung disease with a forced expiratory volume in 1 second $<40 \%$ predicted at the time of hemodynamic optimization may be considered a relative contraindication for VAD implant. Significant carbon dioxide retention on a room air arterial blood gas is a sign of advanced chronic obstructive pulmonary disease. Recognition of the coexistence of pulmonary parenchymal pathology with pulmonary vascular hypertension is essential because this condition predisposes to perioperative right heart failure. Advanced idiopathic pulmonary fibrosis should be considered a contraindication for VAD implant. ${ }^{37}$

\section{Infection}

Patients with active systemic and/or localized infection should not be considered for LVAD therapy until the infection is adequately treated. Leukocytosis and fever must be thoroughly investigated preoperatively and 
appropriate cultures and imaging studies obtained. Furthermore, it is critical to identify patients who are at high risk for developing infections, such as those with poorly controlled diabetes, malnutrition, immunocompromised state, receiving mechanical ventilation, or with multisystem organ failure.

\section{Nutrition/Body Mass Index}

Comprehensive preoperative evaluation should include a nutrition assessment and formalized plan to initiate nutritional support while addressing the metabolic imbalances associated with heart failure. A thorough physical exam focused on frailty and muscle mass is vital. A correlation between poor nutrition and increased morbidity and mortality following cardiovascular surgery has been demonstrated. ${ }^{38}$ Markers of suboptimal nutritional status before LVAD implantation include body mass index $<20$, albumin $<3.2 \mathrm{mg} / \mathrm{dL}$, prealbumin $<15 \mathrm{mg} / \mathrm{dL}$, total cholesterol $<130 \mathrm{mg} / \mathrm{dL}$, lymphocyte count $<100$, and purified protein derivative skin test anergy. ${ }^{39}$

Both extremes of body mass index, obesity, and cachexia increase the risk for mortality and morbidity post-VAD implant. ${ }^{40-42}$ Although obesity is common in patients with heart failure and body mass index $>40$ was an exclusion criterion in both the HeartMate II (Abbott Laboratories, Chicago, Ill) BTT and DT trials, obesity remains only a relative contraindication to continuous-flow LVAD implantation. Published reports provide conflicting evidence as to whether obesity is associated with adverse outcomes after $\mathrm{LVAD}^{40-43}$; cachexia (body mass index $<22$ ) has consistently been identified as a risk factor for perioperative death. ${ }^{38,39,42}$

Current devices provide adequate support for obese patients, and although issues regarding infection are a consideration, outcomes more likely depend on accompanying comorbidities rather than the obesity itself. Because durable LVAD implantation is generally applied in the setting of acute decompensation, and in light of the tenuous hemodynamic status of these patients, strategies to address obesity first with bariatric surgery are not practical. General consensus exists that amelioration of the heart failure state with LVAD support in obese and nonobese patients is not associated with weight loss and in fact, frequently results in weight gain. ${ }^{44,45}$

\section{Neurological/Neurocognitive Evaluation}

Patients at risk for or have a history of cerebrovascular disease and those with a carotid artery bruit should undergo carotid duplex ultrasonography to rule out obstructive carotid artery disease. In patients with ischemic cardiomyopathy, imaging of the ascending aorta and arch with chest computed tomography scanning can be used to rule out aortic disease that may preclude LVAD implantation due to high risk of embolization during construction of the outflow graft anastomosis. As neurological complications may arise while on LVAD therapy, a head computed tomography scan or magnetic resonance imaging can be useful to establish a baseline, particularly in patients with a history of stroke. Detailed neurocognitive evaluation is advisable in patients with cognitive impairment to ascertain ability to comprehend and manage the LVAD. In general, patients with substantial neurologic deficit and/or neurocognitive disabilities are not offered MCS.

\section{Psychosocial}

Even in the presence of optimal medical and anatomic features, major psychosocial issues may present important barriers to long-term outcomes following LVAD implant $^{46,47}$ and require preoperative evaluation. Psychiatric disorders, substance abuse, history of noncompliance, lack of family or caregiver support, and lack of adequate insurance coverage for appropriate chronic LVAD care should be identified and addressed before LVAD implant.

\section{Hemodynamic Parameter Optimization}

Treating volume overload. Elevated filling pressures should be treated with intravenous loop diuretics and, if needed, thiazide diuretics. In patients with diuretic refractory volume overload, ultrafiltration or even hemodialysis may be used, but the need for such therapies identifies patients at higher risk for post LVAD renal dysfunction and poor outcomes. ${ }^{48}$ If the patient has a low output state, the excess volume cannot be adequately addressed independent of efforts to improve cardiac output. ${ }^{49}$

Inotropic support. In the setting of advanced heart failure, administration of inotropic agents is a first line of therapy, usually simultaneous with adjustment of intravascular volume. Increase in cardiac output secondary to augmentation of contractility may be sustained or temporary, depending on the inherent myocardial reserves, state of beta adrenergic receptors, and the severity of multiorgan dysfunction resulting from the low output state. The primary mechanism for most inotropes is an increase in intracellular calcium, either by augmenting influx of calcium during the action potential or by increasing the release of calcium from the sarcoplasmic reticulum. ${ }^{50}$ The 2 most commonly used inotropes in advanced heart failure are dobutamine (primarily a beta-1 agonist with some beta- 2 effects) and milrinone (a phosphodiesterase-3 inhibitor that increases intracellular calcium) ${ }^{51}$

The use of percutaneous circulatory support devices is discussed in Support Techniques in Cardiogenic Shock section.

Management of PVR. Persistently elevated left-sided filling pressures can lead to passive or reactive elevation of pulmonary arterial pressures and PVR, which is reflected by an elevated TPG. With volume removal and improvements in cardiac output through the use of positive inotropic agents or temporary mechanical support, the TPG and PVR often improve. When pulmonary hypertension is 
unresponsive to these measures, particularly in the presence of RV dysfunction; oral, inhaled, or intravenous pulmonary vasodilators may be considered. ${ }^{52}$ In some cases, despite aggressive treatment, the PVR and TPG remain elevated and are often a reason to move forward with mechanical support rather than transplantation. ${ }^{53}$

\section{SUPPORT TECHNIQUES IN CARDIOGENIC SHOCK}

\section{Intra-Aortic Balloon Pump Support}

Intra-aortic balloon pumps (IABP) provide significant hemodynamic support by increasing stroke volume during balloon deflation and systolic blood pressure during balloon inflation. In the setting of inadequate response to escalating doses of inotropic agents, an IABP may be used to augment cardiac output, although the degree of this augmentation on average is modest, approximately an additional $0.5 \mathrm{~L} / \mathrm{min} .{ }^{54}$ As with patients who present in shock, an IABP may also assist in LV unloading and in the reduction of elevated pulmonary arterial pressures. However, the risks of prolonged IABP include vascular injury, bleeding, and infection. When placed via the femoral artery, an IABP severely limits patient mobility, although some centers have placed the IABP through a graft to the right subclavian artery, which allows for patient mobilization. ${ }^{55}$

In the Intra-aortic Balloon Counterpulsation in Acute Myocardial Infarction Complicated by Cardiogenic Shock II randomized study, there was no 30-day or 12-month mortality benefit for patients receiving an IABP for cardiogenic shock accompanying acute myocardial infarction. ${ }^{55,56}$ Whereas in-hospital mortality was shown to be lower in patients supported by IABP after lytic therapy, ${ }^{57}$ there was no decrease in mortality or multiorgan dysfunction scores with the addition of IABP support after percutaneous intervention for myocardial infarction and cardiogenic shock. ${ }^{58,59}$ However, the overall experience with support in postcardiotomy cardiac dysfunction has been gratifying, and it should be considered a first line of intervention.

\section{Percutaneous/Peripheral Access Assist Devices}

The majority of data supporting the role for percutaneous support was derived from high-risk percutaneous interventions and shock associated with acute myocardial infarction. Compared with IABP, contemporary percutaneous circulatory support devices provide a significant increase in cardiac index and mean arterial pressure; however, reported 30-day outcomes are similar. ${ }^{54}$ Percutaneous devices can provide from 2.5 to $5.0 \mathrm{~L} / \mathrm{min}$ depending on the device, configuration, and pump speed. ${ }^{60,61}$ Percutaneous devices that provide the most flow also typically have the larger catheter sizes and can result in vascular compromise in addition to limiting patient ambulation. However, more novel configurations such as their introduction through a graft anastomosed to the subclavian or axillary artery may allow increased mobility, but at the cost of a more invasive procedure. $^{62}$

Although a period of hemodynamic optimization may allow for decongestion of the lungs, liver, and kidneys; reductions in pulmonary arterial pressures; and improvements in end-organ function, attempts at optimization should not unnecessarily delay the implantation of a durable MCS device. Often 1 to 3 days is sufficient, and if improvements are not seen despite escalation of therapy, then surgically placed temporary support may be needed or the patient's appropriateness for permanent support should be reconsidered.

Left atrium to aorta and $L V$ to aorta percutaneous technologies. The TandemHeart pVAD (TandemLife Inc, Pittsburgh, Pa) consists of a proprietary inflow cannula for transseptal drainage from the left atrium, a centrifugal pump, and a femoral artery cannula for systemic arterial return. Despite the technical requirements, transseptal drainage reduces LV end diastolic pressure and largely eliminates concerns of pulmonary injury common to the venoarterial extracorporeal membrane oxygenation (VA ECMO) approach. In a multicenter randomized trial, hemodynamic improvements with the TandemHeart pVAD were significantly better than those seen with IABP. ${ }^{63}$ Nonetheless, no study has demonstrated a 30-mortality benefit for the TandemHeart pVAD in cardiogenic shock.

The LV to aorta percutaneous approach is exemplified by the Impella (Abiomed Inc, Danvers, Mass) transaortic micro axial devices that improve hemodynamic parameters by direct antegrade unloading of the LV without increasing LV afterload. Despite significant improvement in hemodynamic parameters, a small randomized clinical trial exploring the use of the Impella 2.5 device did not demonstrate a 30-day mortality benefit when compared with IABP. ${ }^{64}$ A study from the EuroShock registry confirmed the perfusion benefits but poor 30-day survival of this technology. ${ }^{65}$ Hence, despite superiority in hemodynamic support with reduced capillary wedge pressure, reduced lactate levels, and improved cardiac indices and mean blood pressures, neither of these technologies has shown a survival benefit in patients with cardiogenic shock. No data exist on the use of the larger Impella devices that deliver higher flows that, in theory, would be of greater benefit for desperately ill patients in cardiogenic shock. A recent meta-analysis of six studies evaluating the use of a larger flow device (eg, Impella 5.0) suggested favorable survival and myocardial recovery outcomes. $^{66}$

ECMO. Composed of a circuit that includes a centrifugal pump, a membrane oxygenator, and venous and arterial cannulae, the broad availability, technical simplicity, and rapid deployment inherent with these systems have made VA ECMO the treatment of choice for cardiogenic shock. However, despite broad application of the 
technology, hospital discharge outcomes remain poor with collective survival approximating $35 \% .{ }^{67}$ ECMO has been used for postcardiotomy shock, allograft failure, fulminant myocarditis, and decompensated heart failure among other indications. The increasing utilization of VA ECMO for patients in cardiogenic shock is based on expert opinion and community consensus in the absence of randomized controlled trials. In general, extracorporeal life support (ECLS) is an effective method of resuscitation in moribund patients. Efficacy is contingent upon early deployment, limitation of device and deployment comorbidities, and the potential of myocardial and end-organ recovery. Several recommendations based on expert consensus can be put forward with regard to ECMO use and management. First, whereas revascularization is the best option for acute myocardial ischemia, in the setting of cardiogenic shock, revascularization delays definitive support and increases end-organ injury. Mechanical circulatory support can provide a resuscitation platform for revascularization and improve patient outcome. ${ }^{68}$ Secondly, bleeding and ischemia complicate device deployment in $30 \%$ of patients. ${ }^{69}$ Regardless of percutaneous or open approaches to femoral cannulation, any surgical bleeding is unacceptable, and distal perfusion of the lower extremity is considered standard of care. Central cannulation is underutilized and has been shown to improve survival in pediatric patients. ${ }^{70}$ Third, in the absence of early myocardial recovery, retrograde arterial flow increases LV afterload and end diastolic pressure, and promotes LV thrombus formation and pulmonary edema with subsequent lung injury. ${ }^{71}$ Decompression of the compromised LV is mandatory with femoral VA ECMO, and patients should not be supported long term with retrograde flow in the absence of improving cardiac function. IABP counterpulsation antegrade flow LV-to-aorta micro axial unloading, apicoventricular cannulation, interatrial septostomy, and direct decompression of the left atrium have all been described to successfully lower atrial pressure and prevent or limit lung injury.

Although there are several technologies available to patients with malperfusion, patients in circulatory arrest frequently require salvage ECMO during ongoing extracorporeal cardiopulmonary resuscitation (eCPR). eCPR is defined by the Extracorporeal Life Support Organization as "the use of extracorporeal life support (ECLS) in patients with cardiac arrest when conventional resuscitative measures have failed" (https://www.elso.org/ Portals/0/Files/ELSO_Recirculation_guideline_May2015. pdf). We restrict the definition of eCPR to those patients with pulseless electric activity arrest and so-called cardiac standstill (ie, asystolic cardiac arrest). There are no randomized controlled trials to support the use of eCPR in adult resuscitation. Propensity score-matched cohort analysis suggests that hospital discharge and long-term survival is higher among in-hospital cardiac arrest patients treated with eCPR. ${ }^{72}$ However, the resuscitation interval before eCPR and spontaneous return of circulation remain the most significant predictors of survival. Door-toimplantation time of ECLS systems predicts mortality in patients with witnessed out-of-hospital cardiac arrest. ${ }^{73}$

Right-sided support. A percutaneous right-sided (ie, right atrium-to-pulmonary artery) Impella RP (Abiomed Inc) device is also available and has been less intensively studied. Two small series show promising 30-day survival rates of $72 \%$ and $73 \%$, respectively. ${ }^{74,75}$ In a majority of these cases, shock occurred in the setting of RV failure following transplantation or LVAD implantation. Another RV support system is the Protek Duo RV support device (LivaNova, London, United Kingdom), which consists of a percutaneously placed dual lumen cannula that is inserted through the right internal jugular vein and advanced over a wire into the main pulmonary artery. If needed, an oxygenator can be inserted into the system, which is designed to allow patient mobilization. (See further discussion on right-sided devices in the Biventricular Support section.)

\section{BIVENTRICULAR SUPPORT \\ Biventricular Failure: Etiologies}

Biventricular failure (BVF) occurs when both chambers of the heart show evidence of inadequate forward flow with appropriate filling pressures, compromising adequate oxygen delivery and maintenance of normal physiologic function. $^{76,77}$ The etiology for RV failure ${ }^{78}$ can be primary, electromechanical in nature, or secondary to LV and/or pulmonary etiologies. Furthermore, RV failure can be transient and respond to medical management and/or temporary mechanical support or might be irreversible or unresponsive to the best management. The definition of failure for each ventricle is based on hemodynamic and structural criteria that are better understood for the LV and less so for the RV. The hemodynamic definition of BVF, despite etiology, usually includes a cardiac index $<2.0 \mathrm{~L} / \mathrm{min} / \mathrm{m}^{2}$, right atrial pressure and pulmonary capillary wedge pressure $>16 \mathrm{~mm} \mathrm{Hg}$, central venous pressure to pulmonary capillary wedge pressure ratio $>0.63$, and low RV stroke work index. Severe ventricular rhythm disturbances (such as ventricular tachycardia or fibrillation) unresponsive to optimal medical management and electrical ablations usually cause BVF. Etiologies that can cause global cardiac failure, such as restrictive and infiltrative cardiomyopathies (ie, amyloid), can also predispose a patient to BVF. A variety of conditions, including congenital heart disease, ischemic cardiomyopathy (eg, postinfarction ventricular septal defect), cardiac tumors, failing heart transplant graft, and thrombosed ventricles secondary to prolonged ventricular fibrillation while on temporary $\mathrm{MCS}^{76}$ can induce BVF. ${ }^{79}$ 


\section{BVF: Incidence}

The majority of patients with hemodynamic decompensation requiring long-term MCS can be successfully assisted with an LVAD alone, despite the nearly uniform presence of some degree of RV failure. However, there is a group of patients with advanced RV failure who can benefit from initial management with biventricular support that includes biventricular assist devices or cardiac replacement (ie, total artificial heart [TAH]). The incidence of RV failure after LVAD has been reported to be in the range of $10 \%$ to $40 \%$ depending on definitions. ${ }^{80}$ Most of the RV failure occurs in the first few days to weeks after LVAD placement and is often reversible. Multiple risk score models have been derived to predict RV failure severe enough to require biventricular support, ${ }^{81,82}$ but none has gained widespread application.

\section{Indications for Biventricular Support}

In the setting of the aforementioned conditions associated with biventricular involvement; coupled with evidence of severe RV dysfunction on echocardiography, physical signs of right heart failure, and central venous pressure $>16 \mathrm{~mm} \mathrm{Hg}$ after intensive medical therapy, preoperative planning for biventricular support should be initiated.

\section{Methods of RV Support}

If a patient has deteriorated acutely, the most common type of biventricular support is ECMO placed via femoral cannulation (see Support Techniques for Cardiogenic Shock section). Adequate LV decompression must be ensured. The absence of LV ejection or pulmonary capillary wedge $>18$ indicates the need for prompt decompression of the left-sided circulation via $L V$ apex, pulmonary vein, atrial septum, or a percutaneous axial flow pump placed across the aortic valve. Failure to recognize the need for decompression may lead to fatal pulmonary congestion and multiple organ failure.

Temporary biventricular support is most commonly achieved with paracorporeal centrifugal pumps placed percutaneously (see also the Right-sided support section) under fluoroscopy or via sternotomy in the operating room. ${ }^{83}$

Temporary paracorporeal CF devices such as the CentriMag pump (Abbott Laboratories) usually are placed through a sternotomy and can provide LV or RV support. For rightsided support, inflow is from the right atrium with outflow into the main pulmonary artery. Longer-term biventricular support with durable CF pumps has not been approved by the FDA, but is being utilized in an off-label use.

Currently there are pneumatic and CF temporary biventricular assist devices. Pneumatic biventricular assist devices are paracorporeal and pulsatile and have been used in patients as BTT for prolonged periods, but currently are seldom used. ${ }^{84}$ The only heart replacement device (ie, TAH) that is FDA approved for BTT is currently undergoing a DT trial. However, the generally unfavorable midterm outcomes with both the TAH and durable devices used in biventricular support have limited their use to BTT support rather than DT. ${ }^{85}$

The choices of temporary versus longer-term RV and LV devices are dependent on decisions regarding the likely reversibility of RV or LV failure. ${ }^{17,86-88}$ No published guidelines are available for the decision-making process. Patients who appear uniquely suited to TAH include those with restrictive and infiltrative cardiomyopathies and certain forms of congenital heart disease.

\section{SURGICAL APPROACH \\ Operative Planning}

During initial patient evaluation, individual anatomical, physiologic, and technical considerations should be weighed to best assess the benefit-risk ratio of LVAD therapy and determine likelihood of long-term survival. With the average duration of LVAD support increasing and long-term support with CF LVADs going beyond 5 years, surgical techniques have evolved to address potential future issues, including pump thrombosis and progression of valvular disease in addition to the standard consideration of reoperation for transplant. ${ }^{89-91}$

\section{Decision Making}

Three durable CF LVADs have received approval by the FDA. The HeartMate II, an axial flow device, was approved in 2008. The HVAD (Medtronic Inc, Minneapolis, Minn), a centrifugal flow device, was approved in 2012. The HeartMate 3 (Abbott Laboratories), a magnetically levitated CF pump, was approved in 2017.

Data to guide surgical decision making continue to evolve over time. The addition of concomitant procedures has been shown in multiple series to increase short-term morbidity. ${ }^{88}$ Data quantifying the long-term benefit for specific valvular conditions are lacking, with surgeon experience and preference often guiding therapeutic decisions.

Generally accepted concomitant procedures include closure of an atrial septal defect/patent foramen ovale, surgical repair, replacement, or closure of an insufficient aortic valve, and repair of more than moderate to severe tricuspid insufficiency. ${ }^{92,93}$ Additionally, previous mechanical aortic valves are generally treated at the time of LVAD implantation by either re-replacement with a biological valve, patch closure, or entrapment of the mechanical aortic valve but left in situ unaltered in limited cases with unknown risk long-term. ${ }^{89,94,95}$ Similarly, consideration has been given to replacing previous mechanical mitral valves to decrease anticoagulation requirements and possibly reduce the risk of thromboembolism, but definitive data are lacking to guide this decision. ${ }^{96}$ 
Reports noting an increase in early thrombosis with use of the HeartMate II LVAD ${ }^{97}$ have led to an examination of factors, including surgical technique, which may contribute to early pump thrombosis. Pump position has been prominently cited as a potential contributing cause. ${ }^{98}$ This report renewed the call for standardization and consensus in implant conduct. Generally accepted surgical goals for LVAD implantation include creating unobstructed inflow cannula positioning as well as an unobstructed outflow graft path that does not compress the RV. Securing LVAD positioning has been recommended to minimize pump migration. These goals may be consistently achieved in the HeartMate II by generous pump pocket creation, optimized positioning/alignment of inflow cannula and outflow graft, proper pump position in the body, and pump fixation. ${ }^{98}$

Since completion of the Multicenter Study of MagLev Technology in Patients Undergoing Mechanical Circulatory Support Therapy With HeartMate 3 (MOMENTUM 3) clinical trial ${ }^{99}$ and approval of the HeartMate 3, available data indicates the superiority of the HeartMate 3 device over the HeartMate II in terms of the combined end point of survival, freedom from disabling stroke, and freedom from pump thrombosis requiring pump exchange. With current information about the favorable risk profile of the HeartMate 3 , the 2 major long-term devices employed in US clinical practice are the HVAD and HeartMate 3 CF pumps.

All currently available drivelines are partially coated with a polyester velour covering that allows subcutaneous tissue ingrowth. The current consensus is to leave the polyestercovered portion of the driveline completely within at least the subcutaneous and preferentially the rectus driveline path, with the velour-coated junction at least 1 to $2 \mathrm{~cm}$ from the exit site. ${ }^{99}$ In addition, consensus opinion is to anchor the driveline to prevent excessive motion and microtears until healing occurs. The use of a double-path strategy has been suggested as a method to reduce driveline problems long term, but data are lacking. ${ }^{100}$

Placement of LVAD inflow cannula: the usual position of the inflow is 1 to $2 \mathrm{~cm}$ lateral to the left anterior descending coronary artery, in or near the apical dimple. Transesophageal echocardiographic imaging of the apex of the LV under digital pressure or needle insertion aids in determining optimal location. The location of the inflow cannula is critical for both early and long-term pump performance, with the ideal final position of the inflow cannula aligning with the mitral axis and parallel to the ventricular septum. Creating a generous pump pocket with the HeartMate II device is important to prevent inadvertent malposition of the inflow cannula after correct anatomic alignment. The CF devices (eg, HVAD and HeartMate 3) are intrapericardial devices that do not require pump pocket creation.

The location and size of the outflow graft anastomosis can cause turbulence in the aortic root and affect flow over time. Moreover, direction and proximity to the aortic root may play a role in the development of native aortic valve insufficiency. In general, a beveled anastomosis to the anterolateral portion of the midascending aorta is created with an aortotomy that is slightly longer in length than the outflow graft diameter. Excess graft length may lead to kinking of the outflow graft. Short outflow length will increase tension on the anastomosis, leading to anastomotic site bleeding and may cause the graft to constrain the right atrium or ventricle and/or lie closer to the midline, with resulting risk of graft injury during sternal reentry. After outflow graft length is determined, a partial aortic occlusion clamp is placed and the anastomosis performed. Directing the outflow graft toward the right atrial gutter and placing the anastomosis on the lateral aspect of the aorta are strategies employed at LVAD implant to facilitate safer LVAD explant at the time of heart transplantation.

De-airing maneuvers occur throughout the procedure with final de-airing occurring in antegrade and retrograde fashion before weaning from cardiopulmonary bypass.

\section{Median Sternotomy}

All currently FDA-approved CF VADs have defined surgical approaches outlined in the instruction for use publications. The HeartMate II, HeartMate 3, and HVAD device instructions for use define the surgical techniques to include a median sternotomy approach with cannulation of the anteroapical LV and outflow graft anastomosis to the ascending aorta. The HVAD device is the only device currently approved for a left thoracotomy approach and this approach is described in the manufacturers' instructions for use.

\section{Alternative Approaches}

The size of currently available CF LVADs and growing surgical experience has fostered innovation of surgical techniques using alternative nonsternotomy incisions for primary LVAD implantation and exchange. Nonsternotomy approaches include subcostal and left thoracotomy approaches to the LV apex and upper partial sternotomy or a right thoracotomy to perform outflow graft anastomosis. Although most operators have used these approaches to perform standard implantation, others have developed implantation without cardiopulmonary bypass, alternative outflow graft location (axillary/subclavian artery and descending thoracic aorta), as well as robotic implantation. $^{101,102}$ Such nonsternotomy approaches have been reported to achieve lower transfusion rates and shorter length of postsurgical stay as well as offer potential benefits at reoperation for cardiac transplantation. ${ }^{102,103}$ The HVAD LATERAL trial, a multicenter FDA trial, demonstrated noninferiority of the upper hemisternotomy/anterior thoracotomy approach to standard anterior sternotomy (presented at the International Society for Heart and Lung 
Transplantation 2017 Scientific Meeting, April 5-8, 2017, San Diego, Calif), and the FDA approved this application.

\section{MANAGEMENT OF POSTOPERATIVE BLEEDING}

Perioperative bleeding, defined as receiving $>4 \mathrm{U}$ packed red blood cells within 7 days of surgery or requiring a reoperation, is the most common complication after LVAD implantation, with reported rates between $20 \%$ and 81\%. ${ }^{104-106}$ The high incidence following LVAD implantation is a result of preoperative heart failure that contributes to nutritional deficiency, thrombocytopenia, renal insufficiency, and hepatic dysfunction; nonphysiological sheer stress imparted by CF LVADs, with resultant von Willebrand factor deficiency; anticoagulation and antiplatelet medications; pre-existing RV dysfunction; and VAD-specific surgical techniques. ${ }^{107,108}$ The additional morbidity of bleeding is related to increased incidence of infection, respiratory failure due to transfusion associated lung injury, right heart failure, proinflammatory cytokine release leading to pulmonary hypertension, increased chance of allosensitization, and risk of transmission of emerging pathogens not tested for routinely. ${ }^{109-112}$

Preoperative strategies to prevent bleeding include optimizing nutrition and coagulation parameters. ${ }^{113}$ Anticoagulant and antiplatelet medication should be discontinued and any pre-existing coagulopathy corrected before surgery. This might require administration of vitamin $\mathrm{K}$ or fresh frozen plasma or even platelet transfusions. ${ }^{114}$ Optimizing hemodynamic parameters with inotropes or an IABP can help reverse hepatic and renal dysfunction and their related coagulopathies.

Intraoperative management is the most important aspect of prevention of bleeding. The primary class of agents shown to decrease bleeding are antifibrinolytic agents. ${ }^{115}$ Two drugs that can be used are epsilon-aminocaproic acid and transexamic acid. Although not specifically studied in patients with an LVAD, these 2 drugs can decrease bleeding and transfusion requirements after cardiopulmonary bypass. Appropriate dose-dependent reversal of heparin with protamine sulfate is important.

Other important strategies used to decrease bleeding during routine heart surgery that can be applied to LVAD surgery include removal of whole blood before cardiopulmonary bypass to permit return of platelet- and factor-rich autologous blood after protamine reversal, retrograde autologous priming after cannulation to decrease hemodilution, and normothermia during cardiopulmonary bypass. ${ }^{116-118}$

Standard approaches to achieving hemostasis after cardiac surgery should be applied to patients with an LVAD. A thoracotomy approach has also been shown to decrease bleeding compared with standard sternotomy approach to LVAD implantation. ${ }^{19,120}$

There are also additional potential sites of bleeding with LVAD surgery. One is the preperitoneal pocket, especially in the HeartMate II. The pump pocket should be created before heparinization with liberal use of cautery. Intrapericardial devices such as the HVAD, Jarvik 2000 (Jarvik Heart, New York, NY), and HeartMate 3 generally have less bleeding than those requiring extrapericardial placement. Care is required during tunneling of the driveline. Engorged veins or rectus muscle arterial vessels can be injured and lead to significant bleeding. The other 2 LVAD-specific bleeding sites are the apical inflow cannula and the outflow graft-aortic anastomosis. The LV apex can be fragile, especially in elderly patients or patients with prior acute myocardial infarctions. Once the heart is placed back in the pericardium, visualizing and repairing any bleeding is challenging. Many techniques have been described to ensure optimal hemostasis, and they all involve reinforcement with additional prosthetic material. The most common site of bleeding other than the sternum is probably the outflow anastomosis. Multiple suturing techniques have been used, including running, interrupted, and interrupted mattress with pledgets. Sternal management requires particular attention, because most of these patients have some degree of cachexia leading to fragile and osteoporotic bones. In the event of uncontrollable coagulopathy, packing the mediastinum, placing a vacuum dressing, and returning to the operating room later for irrigation and delayed closure have been successfully employed. ${ }^{121}$

Prohemostatic agents are required if measures outlined above are unsuccessful in preventing bleeding and coagulopathy. Guidelines recommend use of fresh frozen plasma when there is a reduction in coagulation factor levels (PT or activated PTT $>1.5$ times the reference level). ${ }^{122}$ Cryoprecipitate is administered for a fibrinogen deficiency $(<100 \mathrm{mg} / \mathrm{dL})$. Platelets can be administered for active bleeding with thrombocytopenia $(<50,000$ platelets per microliter of blood), when abnormal platelet function is contributing to bleeding, or for prophylaxis with a platelet count $<20,000$ platelets per microliter of blood. Although laboratory-based or point-of-care methods (eg, PT, activated PTT, platelet count, and thromboelastography) cannot predict which patients will bleed, they can identify patients who likely have a factor deficiency state and who may benefit from factor replenishment in the face of excessive bleeding. ${ }^{122-125}$

Intractable, life-threatening bleeding can be treated with factor concentrates. Recombinant activated clotting factor VII (NovoSeven; Novo Nordisk, Copenhagen, Denmark) is approved for patients with hemophilia but used offlabel for life-threatening hemorrhage. Although activated recombinant factor VII administration seemed helpful in controlling life-threatening hemorrhage, patients requiring higher doses (eg, 30 to $70 \mu \mathrm{g} / \mathrm{kg}$ ) had a dramatically higher incidence of serious thromboembolic events in patients with an LVAD. ${ }^{126,127} \mathrm{~A}$ randomized clinical 
trial in cardiac surgery patients demonstrated a decrease in bleeding and reoperations, with a numerically higher incidence of thromboembolic events. ${ }^{128}$ Levi and colleagues ${ }^{129}$ reviewed all published randomized placebocontrolled trials of activated recombinant factor VII. Among 4468 subjects from 35 trials, 498 had thromboembolic events. There was a statistically significant higher rate of arterial complications compared with venous events, especially in older patients.

Prothrombin complex concentrates contain a standardized amount of factor IX along with various amounts of other vitamin K-dependent factors. The intraoperative use of prothrombin complex concentrates in LVAD patients does not appear to be associated with a significant increase in thromboembolic events; however, larger randomized trials are needed to confirm these findings. ${ }^{130}$ These agents should be used with great caution and only in the setting of life-threatening bleeding.

\section{ANTICOAGULATION MANAGEMENT}

All recipients of CF LVADs require systemic anticoagulation to reduce the risk of device thrombosis and systemic embolization. Presently, relatively few outcome studies have examined optimal anticoagulation strategies for $\mathrm{CF}$ LVAD recipients. The manufacturer's instructions for use for the HeartMate II, HVAD, ${ }^{132}$ and HeartMate $3^{132}$ provide foundational recommendations regarding the use of both antiplatelet and anticoagulant therapies at the time of device implantation and for long-term use.

For recipients of a HeartMate II, ${ }^{131}$ reduced-dose heparin should be initiated in the early postoperative period (1224 hours) once chest tube output has declined to $<50 \mathrm{~mL} /$ h. After 24 hours, the heparin infusion should be titrated gradually to full therapeutic levels over the next 48 hours. Aspirin (81-100 $\mathrm{mg}$ daily) and dipyridamole (75 $\mathrm{mg} 3$ times daily) should start on postoperative day 2 or 3 . Warfarin should commence on postoperative day 3 to 5 , overlapping with heparin. The INR should be maintained in the range of 2.0 to 3.0. The HeartMate II manufacturer's instructions for use suggests dual antiplatelet therapy, but few centers choose to observe this practice.

Similar anticoagulation recommendations are provided for the HVAD, ${ }^{132}$ with a recommendation that anticoagulation therapy be individualized for each patient. Heparin should be initiated at low doses and increased gradually to achieve full heparinization. Long-term oral anticoagulation therapy should consist of a combination of warfarin (INR, 2.0-3.0) and aspirin $325 \mathrm{mg}$ daily. It is recommended that if the antiplatelet therapy chosen is aspirin alone, one should check for acetylsalicylic acid resistance with a reliable test. Multidrug options include aspirin $81 \mathrm{mg}$ plus Aggrenox (aspirin $25 \mathrm{mg}$ and dipyridamole $200 \mathrm{mg}$ ) (Boehringer Ingelheim Pharmaceuticals Inc, Ridgefield, Conn) or aspirin $81 \mathrm{mg}$ plus clopidogrel $75 \mathrm{mg}$ daily.
Clopidogrel may be used as an aspirin alternative in intolerant or allergic patients. Warfarin should be started on postoperative day 4 , overlapping with heparin.

Recommendations from the manufacturer regarding anticoagulation therapy in conjunction with implantation of the HeartMate 3 device ${ }^{131}$ include intravenous heparin initiated after 12 to 24 hours or when chest tube drainage is $<50 \mathrm{~mL} / \mathrm{h}$ over a 2 - to 3 -hour period. Low-dose heparin is recommended over the first 24 hours, after which heparin is gradually titrated to achieve therapeutic levels over the next 48 hours. On postoperative day 2 to 3 , aspirin is initiated at 81 to $100 \mathrm{mg}$ daily. On postoperative day 3 to 5 , if no evidence of ongoing bleeding is observed, warfarin is started (overlapping with heparin until INR is stable at or above 2.0). The INR should be maintained in a range of 2.0 to 3.0.

Common practice is to monitor unfractionated heparin activity by measuring PTT. Alternative strategies include antifactor Xa monitoring and protamine titration. There appears to be a poor correlation between antifactor Xa levels and activated PTT in patients with a CF LVAD. ${ }^{133}$ Upon closer examination, the correlation in patients with a $\mathrm{CF}$ LVAD in whom there is no suspicion of pump thrombosis, in particular those being bridged to a therapeutic INR, is reasonably reliable. ${ }^{134}$ On the other hand, this correlation is less reliable in the setting of suspected pump thrombosis, whereby elevated levels of plasma free hemoglobin resulting from hemolysis may lower antifactor Xa activity levels. Adjusting unfractionated heparin levels to achieve therapeutic antifactor Xa in this setting may lead to supratherapeutic PTTs and higher bleeding risk. ${ }^{134}$

Novel oral anticoagulants offer an attractive alternative to vitamin $\mathrm{K}$ antagonists such as warfarin because they do not carry any dietary restrictions, provide a predictable level of systemic anticoagulation, and do not require therapeutic drug monitoring. ${ }^{135}$ The novel oral anticoagulants are approved for stroke prevention in the setting of nonvalvular atrial fibrillation and for the prevention and treatment of deep venous thrombosis. Their safety and efficacy in patients with a CF LVAD have not been established. The early termination of a phase II trial of dabigatran in recipients of mechanical heart valves due to an excess number of ischemic strokes should raise concern for using novel oral anticoagulants outside of their approved indications. ${ }^{135}$

The highest priority in the face of major active GI or recent intracerebral bleeding is temporary return to a near-normal coagulation profile. There are currently no established guidelines for duration of cessation or timing of re-initiation of anticoagulation following resolution of the bleeding event.

\section{OPTIMIZING PUMP SPEED}

The goal of pump speed adjustment is to improve the abnormal hemodynamic parameters of congestive heart 
failure by unloading the LV and establishing forward cardiac output. Optimization of pump operation must take into account the effect of high versus low pump speed on $\mathrm{RV}$ function, blood pressure, and aortic valve opening. In addition, considerations in the immediate postoperative period differ from those during long-term support. Lastly, device-specific LV unloading characteristics may determine metrics of optimal device performance.

\section{Early Postoperative Phase}

Speed adjustments should be hemodynamically guided to provide optimal end-organ function and allow weaning of vasopressors as the patient is recovering from the vasodilatory state usually induced by LVAD implantation. ${ }^{136}$ In this setting, care must be taken not to set pump speed too high to avoid leftward septal shift and induction of RV failure. ${ }^{137}$ Initial speed setting is undertaken in the operating room with direct visualization of the interatrial and interventricular septae by transesophageal echocardiography. Aortic valve opening is not an important goal at this stage and higher pump speeds (while avoiding RV failure) will allow favorable LV unloading. Several speed adjustments may be needed to account for the dynamic physiology and vasoactive therapy in this phase.

\section{Chronic Support}

Adequate cardiac output and LV unloading with pulmonary decongestion remain of paramount importance in the long-term maintenance of device-supported patients. A small LV cavity, absence of mitral regurgitation, and a closed aortic valve indicate maximal unloading and may at first glance be equated with an optimized pump speed. Yet there are multiple caveats to the interpretation of these parameters. First, LV cavity size must be adjusted for preoperative cavity size. Second, mitral regurgitation may persist despite achievement of a low pulmonary capillary wedge pressure. ${ }^{138}$ Third, a closed aortic valve may predispose to the development of aortic insufficiency. ${ }^{139}$ Lastly, excessive unloading of the LV may impair the septal contribution to RV function.

Although most available evidence relates to the role of pump optimization in the development of de novo aortic insufficiency, other serious adverse events such as right heart failure and bleeding diathesis are worthy of discussion.

Aortic insufficiency. The association of a closed aortic valve and the development of de novo aortic insufficiency during chronic LVAD support has been reported independently by multiple investigators, uniformly indicating that mild-to-moderate aortic insufficiency will develop in approximately $25 \%$ of patients in whom the aortic valve remains closed after 1 year of support. ${ }^{139-141}$ Only 1 study has examined the relationship of pump speed, aortic insufficiency, and LV unloading, suggesting that the unfavorable hemodynamic effects of severe aortic insufficiency on LV unloading can be overdriven by pump speed. ${ }^{140}$ From the available evidence, it seems reasonable to take aortic valve opening into account when adjusting pump speed. ${ }^{139}$

Right heart failure. Leftward septal shift due to high pump speeds may induce right heart failure and should be avoided. The balance of RV unloading by higher speeds and septal shifting may be delicate and difficult to assess.

Bleeding diathesis. CF LVADs via shear stress induce von Willebrand factor deficiency. Of note, this phenomenon has been observed with a large variety of devices, with speeds ranging from 2000 to $10,000 \mathrm{rpm}$ and various gap sizes. ${ }^{142-145}$ Thus, it is unlikely that speed adjustment on a given device (eg, HeartMate II speed, 9000 down to $8600 \mathrm{rpm}$ ), would lead to avoidance of von Willebrand factor deficiency. Recent laboratory evidence supports the notion that destruction of large multimers is not affected by pump speed across the operating range of the HeartMate II (C. Bartoli, ISRBP, unpublished data, 2017). Animal ${ }^{146}$ and clinical studies suggest that decreased pulsatility may create a favorable environment for intestinal angiodysplasia and the development of arteriovenous malformations that may be precursors for GI bleeding. ${ }^{147}$ However, the possibility that an opening aortic valve and some pulsatility could decrease the incidence of GI bleeding has not been validated in clinical studies.

\section{Device-Specific Performance Characteristics and Implications for Pump Speed Adjustment}

Ramp studies have been developed to assess performance of centrifugal flow LVADs in the setting of suspected device thrombosis. The slope of change of the LV end diastolic diameter during stepwise speed increase of the HeartMate II is associated with pump thrombosis. It is important to recognize that the effects of axial flow and CF devices on LV end diastolic diameter are entirely different. Thus, device-specific performance characteristics need to be taken into account when optimizing pump speed. ${ }^{148}$ Absence of a reduction of $\mathrm{LV}$ end diastolic diameter during an HVAD ramp, for example, cannot be equated with failure to unload.

\section{DIAGNOSIS AND MANAGEMENT OF PUMP MALFUNCTION \\ Diagnosis of Pump Malfunction}

The clinical presentation of a dysfunctional LVAD may range from subtle and asymptomatic to catastrophic with cessation of device function. Optimal device monitoring requires a systematic, multimodality approach that integrates historical features; physical examination findings; serological evaluation; cardiac imaging; and in some instances, hemodynamic assessment. Potential failure mechanisms must be accurately and expediently assessed to detect 
abnormalities sufficiently early to minimize the potential for patient harm.

A carefully performed history of symptoms, device function, and alarms is a critical component of device monitoring. An appropriately functioning LVAD should alleviate left heart failure symptoms. ${ }^{149}$ A VAD-supported patient with symptoms of left heart failure, including dyspnea or excessive exertional fatigue should prompt device evaluation to ensure optimal speed settings, proper device function, and absence of a mechanical etiology of elevated LV filling pressures such as new or worsening aortic insufficiency. Symptoms or signs of right heart failure, including edema, abdominal fullness, elevated jugular pressure, and an enlarged and pulsatile liver do not necessarily reflect device malfunction and may be related to intrinsic $R V$ failure. LVAD dysfunction may directly cause or contribute to RV dysfunction by inadequate unloading of the left heart or unfavorable alteration of RV geometry by excessive unloading with leftward shift of the interventricular septum. However, an unsupported myopathic RV or residual tricuspid insufficiency may equally contribute to right heart failure.

Beyond historical features of heart failure, careful examination of the patient may provide important clues regarding device malfunction. Serial examination of the peripheral pulse should be performed. Most patients on a CF VAD have an undetectable pulse by examination as a result of the reduced pulse pressure. Device dysfunction should be considered in such a patient with a newly detected radial pulse. Examination of the sclera for icterus or the conjunctiva for small hemorrhages may prompt additional evaluation for hemolysis or endocarditis, respectively. Auscultation of the device is not currently a meaningful method to detect device malfunction. Although there are likely changes in device function associated with a characteristic acoustic signal, these have not been sufficiently well characterized to be clinically useful.

\section{Interrogation of the VAD Controller}

Interrogation of the VAD controller at the time of patient evaluation is a critical aspect of understanding pump function. Although specific alarms may be device-specific, several general principles can guide the use of controller information to detect device malfunction. All commercially available LVADs record alarms that detect alterations in device performance. The vast majority of these alarms detect alterations in the amount of energy utilized by the device to maintain rotor speed. For example, development of thrombus on the impeller of an axial flow pump will result in the device requiring more energy to maintain the same speed. As a result, elevated power will be associated with higher pump flows (because the flow is a calculated value that integrates speed and power). Low-flow alarms indicate a reduction in power consumption that results from reduced VAD preload. Etiologies for low-flow alarms include hypovolemia; right heart dysfunction; ventricular arrhythmias; thrombus overriding the inflow cannula; inflow cannula malposition; and outflow graft kink, twist, or obstruction. Suction events occur when the device recognizes an abrupt reduction in power consumption that is assumed to be from transient occlusion of the inflow cannula. Finally, the controllers track electrical faults displaying disruptions in external power or loss of device function. These latter failure modes are significantly more threatening to patients and nearly always require hospitalization and careful evaluation of the device and external components.

Interrogation of device function should include thoughtful evaluation of serological markers demonstrative of blood cell trauma and end-organ perfusion. Any clinical condition in which reduced systemic perfusion is considered should prompt measurement of serological markers suggestive of altered end-organ function. Perhaps the most sensitive markers of altered perfusion are measures of renal function, including blood urea nitrogen and serum creatinine levels. ${ }^{150}$ Prior studies of VAD support have demonstrated that restoration of a more normal hemodynamic profile results in improvements in blood urea nitrogen and serum creatinine levels. ${ }^{151}$ Demonstration of rising blood urea nitrogen and serum creatinine levels may herald subtle changes in perfusion that require further evaluation. Other markers of altered perfusion include elevated transaminases (aspartate transaminase and alanine transaminase) or INR without change in warfarin dosing. Demonstration of elevated serum B-type natriuretic peptide levels may suggest inadequate ventricular unloading by the VAD or RV failure. Serial serum B-type natriuretic peptide level measurements are likely to be more useful than an isolated measurement because the establishment of a baseline value is critical to appropriate interpretation. Serum lactate measurements may also provide important clinical clues about the status of sufficient perfusion.

Serological markers of hemolysis are the cornerstones of the diagnosis of VAD thrombosis. ${ }^{152,153}$ The most frequently measured markers are serum lactate dehydrogenase (LDH), plasma free hemoglobin, and haptoglobin.

\section{LDH}

LDH is considered the most specific biochemical indicator of pump thrombosis. Elevation $>2.5$ times the upper limit of normal provides a sensitivity of $78 \%$ and a specificity of $97 \%$ for the diagnosis of pump thrombosis and is predictive of thrombus-related events. ${ }^{154}$ The presence of LDH in a wide array of tissues as well as in red blood cells qualify it as a promiscuous marker of hemolysis, so demonstration of simultaneously elevated plasma free hemoglobin is diagnostic of hemolysis. Most programs find useful serial measurement of $\mathrm{LDH}$, a critical component of device monitoring. Early or sustained increases in LDH should prompt 
an evaluation for VAD thrombosis. Further, serum LDH can be used to assess the efficacy of device thrombosis therapy. It is important to consider that both axial and centrifugal flow devices may normally be associated with low levels of hemolysis in the range of 250 to $350 \mathrm{IU} / \mathrm{L}$, which is not indicative of pump thrombus. Generally, baseline LDH runs higher in axial flow devices compared with centrifugal devices. ${ }^{154}$ Therefore, it is also important to consider device type and trends over time when evaluating LDH levels. LDH may also come from other sources, including the liver, lungs, and muscle. In some cases it may be necessary to perform testing of $\mathrm{LDH}$ isoenzymes to identify a red blood cell source of LDH elevation.

\section{Plasma Free Hemoglobin}

The INTERMACS definition of hemolysis is a plasma free hemoglobin value that exceeds $40 \mathrm{mg} / \mathrm{dL}$ in association with clinical signs of hemolysis (eg, anemia, low hematocrit, and hyperbilirubinemia) occurring after the first 72 hours postimplant. Hemolysis related to documented nondevice-related causes (eg, transfusion or drug) is excluded from this definition. Plasma free hemoglobin $>40 \mathrm{mg} / \mathrm{dL}$ should raise concern for possible thrombus. ${ }^{155}$ Plasma free hemoglobin is usually elevated with pump thrombosis and hemolysis. However, it is less sensitive than LDH levels in detecting device thrombosis ${ }^{154,156}$ with results taking several days to be delivered. Finally, a haptoglobin drop can signal hemolysis and pump thrombosis but can be already decreased due to subclinical hemolysis in a normally functioning VAD.

\section{Other Laboratory Parameters}

In addition to LDH and plasma free hemoglobin, other lab abnormalities associated with hemolysis include elevation of bilirubin, decrease in hemoglobin/hematocrit levels, and increase in creatinine and blood urea nitrogen levels.

\section{Cardiac Imaging}

Cardiac imaging provides valuable information about VAD function. ${ }^{157,158} \mathrm{~A}$ posteroanterior and lateral chest radiograph is used to evaluate the positioning of the device and inflow cannula. Demonstration of inflow cannula angulation toward the ventricular septum or lateral wall in the setting of ventricular arrhythmias or frequent suction events suggests inflow cannula malposition. Radiographic interrogation of the intracorporeal and extracorporeal components of the driveline should be undertaken in patients presenting with electrical faults to evaluate the integrity of the wires and supporting structures.

Echocardiography is a cornerstone of LVAD evaluation, particularly when device malfunction is suspected. ${ }^{158,159}$ Transthoracic echocardiography can be useful to evaluate LV size and the status of aortic valve opening. Demonstration of increased LV size or new aortic valve opening suggests that the VAD is not unloading the ventricle sufficiently and should prompt a ramp test in which the VAD speed is gradually increased under echocardiographic guidance to determine the ability of the pump to reduce ventricular size and eliminate aortic valve opening. Failure to change ventricle size or aortic valve motion at high VAD speed is strongly suggestive of device malfunction. ${ }^{158}$

Transthoracic echocardiography is a useful adjunctive test to understand positioning of the inflow cannula in the LV in relationship to the myocardium. The role for transesophageal echocardiography is more limited in the evaluation of device malfunction but may be particularly useful in cases in which the body habitus does not permit adequate assessment with a chest wall study or when more careful evaluation of the native cardiac valves is required.

Chest computerized tomography is the final imaging study that can be particularly useful to clinicians attempting to understand the cause of VAD malfunction. ${ }^{157}$ Gated, contrasted computed tomography allows careful evaluation of the inflow cannula position that can often demonstrate continuity of the cannula with ventricular myocardium. Further, computed tomography provides a unique opportunity to evaluate the outflow graft to exclude the possibility of alterations in structure or intraluminal thrombus. In general, normally functioning LVADs reduce the pulmonary capillary wedge pressure and improve cardiac output. ${ }^{158}$

In the setting of device malfunction, these hemodynamic parameter goals may not be accomplished, resulting in symptoms of left (or right) heart failure. Direct hemodynamic measurement can be useful in the assessment of a patient in whom VAD dysfunction is considered. Demonstration of a pulmonary capillary wedge pressure $>18 \mathrm{~mm} \mathrm{Hg}$ or cardiac index $<2.2 \mathrm{~L} / \mathrm{min} / \mathrm{m}^{2}$ should prompt an evaluation of appropriate pump speed and/or device malfunction.

\section{Frequency of Surveillance}

The ideal frequency of surveillance for pump thrombosis has not been established. Because pump thrombosis and hemolysis can occur at any time while on mechanical support, patients should be evaluated at regular intervals with clinic visits, surveillance biochemical studies, and imaging. Monthly evaluation of LDH and plasma free hemoglobin has been suggested by a disease management model and by expert consensus. ${ }^{108,160}$

\section{Pump Thrombosis}

Pump thrombosis is among the most common reasons for replacement of MCS devices. In multiple retrospective reviews, the incidence of pump thrombosis as the cause for replacement ranges from $29 \%$ to $50 \% .{ }^{153,161-163}$ The INTERMACS database reported an overall prevalence for the HeartMate II of 5.5\% ${ }^{161}$ The incidence of thrombosis in all patients with VAD was initially reported to be between 
$2 \%$ and $4 \%$ by 6 months (2008-2009 data), but more recent data (2012-2013 data) indicated a 7\% to $8 \%$ incidence of pump thrombosis by 6 months. ${ }^{97}$ Data from the long-term HeartMate 3 trial demonstrated a $1 \%$ incidence of pump thrombosis at 24 months. ${ }^{164}$

The etiology of pump thrombosis is incompletely understood but is device-specific and multifactorial. Factors can be categorized into pump-related, patient-related, and management-related. Pump-related factors include intrinsic heat from the impeller, shear stress resulting in platelet aggregation, cannulation site thrombosis, outflow graft impingement, and inflow cannula migration or malposition. Patient-related factors include pre-existing atrial or ventricular thrombus, atrial fibrillation, left side mechanical prostheses, ventricular failure, and hypovolemia. Managementrelated contributors include low INR, absence of antiplatelet therapy, infection management, and low revolutions per minute setting. Preventing this complication requires a technically sound operation as well as careful device and anticoagulation therapy management. ${ }^{165}$

Available treatment strategies for LVAD thrombosis include intravenous anticoagulants (eg, unfractionated heparin or direct thrombin inhibitors), ${ }^{166,167}$ antiplatelet agents, ${ }^{168}$ thrombolytics, ${ }^{169}$ or device exchange. ${ }^{170}$ The choice of initial therapy for the patient with LVAD pump thrombosis, irrespective of the pump type, depends on several factors, including patient presentation, surgical candidacy, and institutional philosophy. Compared with pump exchange that has an increased mortality in the perioperative period, medical treatment of pump thrombosis may be associated with a high rate of treatment failure, recurrent thrombosis, or the eventual need for pump exchange or cardiac transplantation. ${ }^{171}$ The mortality for patients with pump thrombosis increases after each subsequent pump exchange. ${ }^{172}$

Patients with a suspicion of LVAD thrombosis should be urgently transferred to a quarternary-care center with expertise in MCS. In case of hemodynamic instability, patients should be transferred to an intensive care unit for close monitoring and initiation of therapy with anticoagulation and heart failure medications. Preparation for pump exchange usually includes therapy with necessary inotropes and diuresis.

\section{Medical Management}

Medical management for pump thrombosis is associated with a high morbidity, high proportion of treatment failures, and the need for pump exchange when balanced with a modest success rate, especially if the onset of the thrombosis is $>24$ hours. ${ }^{173,174}$ Starling reported a $50 \%$ mortality in those initially treated medically, compared with a $2.3 \%$ mortality in those who underwent immediate device replacement. ${ }^{153}$ The decision to use pharmacologic treatment in the management of device thrombosis and the specific selection of drugs used is actually device and center specific. Further studies are needed because the literature thus far is limited to case reports and case series with no randomized clinical studies available.

There are limited data for the use of direct thrombin inhibitors such as argatroban and bivalrudin aside from retrospective case series. ${ }^{175}$ A proposed algorithm for the diagnosis and management pump thrombosis according to clinical presentation and utilizes intravenous heparin in the setting of hemolysis as a single-treatment modality. Heparin alone seems to be less successful for clot resolution via fibrinolysis.

Resolution of clinical findings (eg, power spikes, hemolysis, and/or heart failure) can be followed by up-titration of antithrombotic therapy with aspirin $325 \mathrm{mg}$ and warfarin to an INR target of 2.5 to $3.0 .{ }^{176-178}$ Consideration can be given to the addition of a second antiplatelet agent (eg, clopidogrel or dipyridamole). ${ }^{177,179}$

Persistent hemolysis, powerspikes, and/or heart failure symptoms may be addressed with more aggressive antithromobotic therapy with direct thrombin inhibitors (eg, eptifibatide or tirofiban). Small case series have suggested the use glycoprotein inhibitor with or without additional intravenous anticoagulants for suspected device thrombosis. The evidence and effectiveness of these therapies is uncertain and can cause severe bleeding complications. ${ }^{174,180-185}$

Thrombolytic agents can be administered peripherally or centrally. A collection of case reports and larger case series have documented outcomes after treatment with intraventricular and intravenous recombinant tissue plasminogen activator with several different pumps. Although these limited studies demonstrate a high success rate with low morbidity, an analysis of larger series demonstrate success rates ranging from $20 \%$ to $75 \%$ with much higher mortality rates. Treatment of thrombus events with recombinant tissue plasminogen activator in the ADVANCE Pivotal Trial for BTT indication and its subsequent continued access protocol enrollment reported an overall success rate of $63 \% .{ }^{162}$ As such, thrombolysis has not undergone rigorous clinical evaluation in patients with an LVAD and should be used with extreme caution. Intravenous thrombolysis ${ }^{174,180-185}$ is associated with an important risk of severe bleeding complications (eg, hemorrhagic stroke), but can be considered if a patient is not a surgical candidate. ${ }^{13,162,173,176,179,182,184,185}$ Intraventricular thrombolysis ${ }^{169,180,186-191}$ should be also be used with extreme caution because of the risk of severe bleeding, but can be considered if the patient is not a surgical candidate. ${ }^{162,169,171,187,188,190-192}$

\section{Surgical Pump Exchange}

Currently, pump exchange is the established gold standard treatment for pump thrombosis. Surgical pump exchange is a definitive treatment of pump 
thrombosis. ${ }^{105,165,193}$ Pump thrombus requiring exchange with the HVAD occurred at a rate of 0.04 events per patient-year. Previous studies with axial flow LVADs evaluating pump thrombosis focused on pump thrombus requiring surgical exchange and reported exchange rates of 0.014 to $0.04 .^{105,165,193}$ Good outcomes have been reported after device exchange in experienced centers and when using a subcostal surgical approach. ${ }^{106,149,193-195}$ The safety of surgical pump exchange was emphasized by Moazami and colleagues ${ }^{193}$ with a 30-day mortality of $6.5 \%$ reported among 77 HeartMate II replacement procedures performed through a left subcostal approach. Surgical therapy in patients with an HVAD was successful, with no early deaths or major nonfatal morbidity. As part of the operative planning, a contrast-enhanced computed tomography scan and a thorough echocardiographic evaluation is advisable to rule out anatomic causes of pump thrombosis. If any of these evaluations suggest malposition of the inflow cannula with related dynamic inflow obstruction or kinking or compression of the outflow graft, then a complete pump exchange through a re-do median sternotomy is indicated because the subcostal approach limits the exchange to the body of the pump. The subcostal approach can be done on-pump (through peripheral cannulation) or off-pump depending on ventricular reserve and hemodynamic stability of the patient.

The intrapericardial location and the configuration of centrifugal pumps require direct access to the LV apex. Although sternotomy offers reasonable access, often mobilization of the LV apex will be extremely difficult and this approach can be hazardous. A left thoracotomy allows direct access to the apical pump and is also feasible.

Urgent transplantation can be pursued as a therapy of choice if the estimated wait time is short, heart failure and end-organ function can be managed, and the patient is otherwise a suitable candidate.

Weaning and device explanation can be pursued and is the therapy of choice for patients with recovery of ventricular function.

\section{Mechanical Device Failures}

The most common reason for device malfunction is percutaneous lead damage. In a large cohort encompassing 47 centers, $3 \%$ of all HeartMate II implants required replacement for lead damage, with $1.7 \%$ related to external issues. ${ }^{193}$ This complication accounted for $46 \%$ of replaced devices. These results led to a device change in June 2007, decreasing the incidence from $4.5 \%$ to $1.5 \%$. It should be noted that there were no mechanical failures of the pumping mechanism in this cohort. Often, for this complication, only the main pump body needs to be exchanged, leaving the inflow and outflow conduits intact. This can be approached utilizing a subcostal incision or a limited sternotomy.
MANAGEMENT OF PUMP-RELATED INFECTIONS

Infections in LVAD patients have been categorized by an International Society for Heart and Lung Transplantation consensus conference into 3 categories: VAD-specific, VAD-related, and non-VAD-related. ${ }^{196}$ VAD-specific infections in turn can be broken down into power cord, pump pocket, and internal surfaces (pump or cannula) infections. ${ }^{197}$ The VAD-related infections refer to infections not directly involving the VAD itself but possibly occurring as a result of VAD placement. This category would include mediastinitis and bloodstream infections in which it is unknown whether LVAD surfaces harbor bacteria. Patients with an LVAD may present with positive blood cultures without clear understanding of the source of the bacteremia. Some of these patients may have a VAD-specific infection but, in many instances, the exact nature of the infection cannot be initially defined. The non-VAD-related infections include pneumonia and urinary tract infections. These guidelines pertain mainly to VAD-specific infections.

Because of the large surface area of the pump exterior, plus the tendency for blood to accumulate around the pump during and after implant, prophylactic measures are advisable to reduce pump-related infection risk following implant. Pathogenic bacteria (eg, methicillin-resistant Staphylococcus aureus) from sites such as the nose or perineum may pose an additional risk for postimplant infection. Rapid screening for nasal or perineal methicillin-resistant $S$ aureus based on polymerase chain reaction assays to identify patients colonized with methicillin-resistant $S$ aureus, followed by application of topical antimicrobial agents to eradicate methicillin-resistant $S$ aureus, may reduce the rate of sternal infection after cardiac surgery. ${ }^{198}$ The most common intravenous prophylactic antibiotic regimens for LVAD surgery include vancomycin, cefazolin, and fluconazole for 24 hours. ${ }^{198,199}$

Device-related infection in recipients with MCS devices is an important source of morbidity and mortality. Parallel research in the field of microbiology has also helped clinicians understand the propensity of certain bacteria to infect implanted blood pumps and percutaneous drivelines. ${ }^{200}$ Bacteria capable of forming protective slime layers to resist host defenses and antimicrobial agents are the most common and persistent causes of device-related infections. In addition, bacterial adhesion molecules specific for MCS device surfaces and bacterial enzymes capable of disrupting healed tissue (eg, collagenases) pose threats to the longterm success of implanted MCS devices.

Current management of driveline and pump pocket infections is based on personal experience and information from retrospective studies. The majority of the retrospective studies are from single institutions, although there are a few multicenter reports. The most notable of the multicenter reports are those based on INTERMACS. ${ }^{48}$ There are no 
Level A recommendations for management of infection due to the absence of prospective, randomized, multicenter trials and meta-analyses of prospective randomized trials. Similarly, the 2013 Guidelines for Mechanical Circulatory Support reported levels of evidence for infection prevention and management from $\mathrm{B}$ to $\mathrm{C}{ }^{108}$ The publication of consensus-based guidelines that standardize definitions for infections in patients with VADs are important for improving outcomes. ${ }^{196}$

\section{Driveline Infection}

The vast majority of LVAD-specific infections are isolated to the driveline, but the infection can secondarily involve the pocket or internal surfaces of the pump. The reported incidence of driveline infection varies, but the risk for driveline infection persists throughout the duration of device implant. In some reports, driveline infection is inevitable. ${ }^{197}$ The prevention of driveline infection begins with surgical technique that minimizes the bacterial inoculum. Clipping hair rather than shaving, the judicious use of prophylactic (ie, perioperative) antibiotics that focus primarily on Staphylococcus spp, and placement of the fabric-covered portion of the driveline completely beneath the patient's skin $^{100,201}$ are steps that minimize the chances of postoperative infection.

Leaving the fabric-covered driveline under the skin but within 1 to $2 \mathrm{~cm}$ of the percutaneous exit site may be important in avoiding exit site infections in humans. Optimal positioning of the driveline establishes a short epithelial lined tract along the nonfabric-coated portion of the driveline. Longer tunnels allow bacteria to thrive adjacent to the velour surface. Certain strains of Staphylococcus epidermidis are particularly adept at adhering to polymers (eg, polyethylene terephthalate) and creating an infected tunnel because the collagen fibers growing into the velour coating are enzymatically destroyed by the bacteria. ${ }^{202}$

In general, diagnosis relies on history, physical examination, laboratory tests, and imaging studies. Patient symptoms may be subtle and include malaise and discomfort at the percutaneous exit site, along the course of the driveline, or over the pump. Erythema, tunneling around the driveline, and purulent drainage are the hallmarks of infection at the driveline percutaneous exit site. Pain and erythema over deeper portions of the driveline and pain in the left lower chest wall or subxyphoid region may indicate deep infections.

Laboratory values include elevation of the leukocyte count with an increase in neutrophils and immature leukocytes (ie, left shift). Fevers are often absent or low-grade. Cultures can be obtained from drainage at the percutaneous exit site; however, contamination of the culture from skin adjoining the driveline may provide misleading culture results.
The most commonly utilized imaging studies to diagnose VAD-related infections are computed tomography scanning and ultrasound imaging. Ultrasound imaging is particularly helpful in planning surgical exploration of deep driveline and pump pocket infections, particularly when there is no overlying erythema to indicate the location of these deep structures. Gallium scans may be useful to delineate extent of infection. Intraoperative fluoroscopy is helpful if obesity or tissues of the chest wall obscure the location of an implanted pump.

The driveline exit site should be inspected frequently by trained personnel while a patient is in the hospital. A mild degree of erythema at the percutaneous exit site is expected with normal healing; however, marked erythema, pain, induration, or purulent drainage indicate exit site infection. Cultures can be obtained to direct antibiotic therapy. Debridement of the exit site is rarely necessary during the initial few weeks of implantation, although an excessive length of nonvelour-covered driveline beneath the skin can lead to early abscess formation because maintaining cleanliness of a long (eg, 3-4 cm) tunnel is difficult.

Driveline infections have been categorized by severity. ${ }^{203}$ Early infections have very little tunneling and consist mainly of induration and erythema at the exit site (ie, cellulitis). As the infection progresses, adhesion between the patient's tissue and the fabric covering the driveline breaks down. Continued infection that is not successfully treated leads to increasing purulent drainage from the driveline exit site and progressive tunneling of the infection along the driveline. It is at this advanced stage that surgical debridement is indicated to expose the tunnel and allow scrubbing of the driveline with disinfectants (eg, hydrogen peroxide or dilute chlorhexidine solutions). The goal is to disrupt any biofilm covering the velour and maximize the chances for reincorporation of the driveline into surrounding tissues. Systemic antibiotics specific to the organisms causing the infection, control of diabetes, and good nutrition are all important to stopping a driveline infection and reincorporation of the fabric by host tissues. Negative pressure devices have been used by several groups to decrease the frequency of dressing changes and encourage wound healing. ${ }^{197,204,205}$

Bacteria that contaminate the deep portion of the driveline at the time of implant may lead to an abscess weeks or months after the initial VAD implant. An abscess is occasionally evident on physical examination due to erythema and induration of skin over the abscess. More commonly, elevation of the leukocyte count, low-grade fever, and positive imaging studies suggest the presence of a deep driveline abscess. The suspicious area can be evaluated by ultrasonography and subsequently explored. Some groups use needle aspiration to sample fluid near the deeper portion of the drivelines. If an abscess is discovered, the area can be treated using open dressing changes with 
packing, a negative pressure device, or methyl methacrylate beads loaded with antibiotic agents (eg, tobramycin and vancomycin). Antibiotic beads often require replacement although they generate very high concentrations of antibiotics in the abscess pocket for a period of roughly 4 to 6 weeks.

Details of optimal driveline management vary from institution to institution. However, they typically include dressing changes performed under sterile conditions until the wound is well healed followed by aseptic dressing changes that periodically (every 1-3 days) ${ }^{206}$ cleanse the skin and driveline at the exit site with a disinfectant (eg, hydrogen peroxide or chlorhexidine). After the percutaneous exit site dries, a dressing is applied that is moisture permeable to prevent skin maceration. The use of a material that elutes an antimicrobial agent (eg, chlorhexidine or silver ions) is used by some groups, whereas others rely only on a dry sterile gauze dressing.

The management of poorly controlled driveline infections remains controversial. The options include wound debridement as described in the previous paragraphs or replacement of the LVAD with re-routing of the driveline to completely avoid the previous driveline path.

There are no prospective randomized trials to compare these methods. The outcomes for patients managed with device replacement are encouraging, ${ }^{193,207-210}$ particularly when heart transplantation follows the exchange. However, this approach subjects patients to the risk of surgery, extension of existing infection to other areas, and the cost of a second pump. The disadvantage of continued management of a driveline infection with debridement and intravenous antibiotics are continued tunneling of the infection, with potential infection of the pump housing (ie, pump pocket infection) and the development of sepsis or ectopic sites of infection due to bacteremia.

\section{Mediastinal VAD-Related Infections}

The etiology of mediastinal VAD-related infections includes several possible sources. The first is bacterial inoculum from the implant operation. The importance of skin preparation and preoperative treatment of methicillinresistant $S$ aureus in carriers is an important first step in minimizing this risk. Longer hospitalization before implant and poor nutritional status as well as INTERMACS level I status are all risk factors for infection, particularly nosocomial infection. It is important to understand that certain organisms, including Staphylococcus spp, can enter a state of extremely low metabolic activity that renders them resistant to antimicrobial agents around the time of surgery, yet allows them to reanimate and cause clinical infections many weeks or months following device implant. A second cause of infection is ascending infection along the driveline tract that finally reaches the pump pocket. It is likely that hematogenously spread infections are a third etiology for pocket infections. Fourth, breaching the integrity of the external portion of the driveline together with a crack in the strain relief at the junction of the driveline and pump housing has occasionally resulted in pump pocket infection. Fifth, surgical technique may predispose to infection (eg, creating on overly large pocket that provides space for hematoma). Lastly, the pump or driveline exit may unintentionally traverse the peritoneum and lead to bowel injury either at the time of implant or later bowel contents may then contaminate the peripump space.

Pump pocket infection presents as postoperative mediastinitis if the infection occurs within the first few days or weeks following device implant. The infection is often widespread and difficult to successfully manage. Delayed infections of the pump pocket are confined by wellformed scar around the pump; they typically cause malaise, low-grade fevers, and new pain in the region of the pump. There may be increased drainage along the driveline or obvious erythema in the subxyphoid region.

Pump pocket infection assessment is typically based on elevated inflammatory markers, echocardiogram, computed tomography scan, and/or labeled white blood cell scintigraphy. Pump exploration is performed through left subcostal or intercostal approach with debridement and abscess fluid drainage. Systemic targeted parenteral antibiotics and continuous irrigation or vacuum assisted drainage are indicated. Once stabilized with negative local cultures as well as bloodstream infection, direct surgical closure or use of a muscle and omental flap may be recommended.

Progression of local and systemic response despite adequate suppressive antibiotic and topical treatment may urge pump explantation (in case of functional recovery only) or complete pump exchange. Even after pump exchange, suppressive therapy should be continued because it is placed in presumably infection-seeded environment.

\section{Management of the Infected VAD at Transplant}

The conduct of the transplant surgery in patients with VAD infection must minimize greater or deeper contamination. In the instance of an infected power cord exit area, the exit site is cleaned and sealed from the rest of the surgical field. Dissection should avoid contact with the infected area, and the power cord could be divided more proximally at a site where it is incorporated and not infected. With this approach, the mediastinum would remain sterile. Following the mediastinal closure, the contaminated exit site is debrided.

Application of a wound suction dressing is useful to facilitate healing of open wound areas. Intravenous antibiotics specific for the organism(s) causing the infection are also warranted. In cases of VAD-specific infection involving blood contacting surfaces, care must be exercised to avoid detachment of vegetations into the systemic circulation at time of device removal. Early application of 
cardiopulmonary bypass, pump stoppage, and aortic crossclamping may be warranted. Furthermore, device handling must avoid contamination of the sterile field from material inside of the pump. Finally, all suspicious areas should be cultured to facilitate appropriate antibiotic agent selection.

Management of central mediastinal or pump pocket infections is most difficult in that the majority of the field may become contaminated. After purulence is encountered or after removal of infected material, the wound can be irrigated with antimicrobial solutions and a new set of sterile instruments should be employed. In these cases, the sternum may be left open after the initial procedure and a delayed soft tissue flap may be employed with or without delayed sternal closure. Potential options for soft tissue coverage include omentum, pectoralis, or rectus muscle. Extensive and prolonged drainage of the affected area is also warranted. Prolonged intravenous antibiotics are indicated. Reduction of early immunosuppression may be appropriate to reduce the risk of recurrent infection. Elimination of induction agents may be a strategy, as well as more rapid weaning of steroids, tempered by results from endomyocardial biopsies to assess rejection. Although survival outcomes after transplantation from infected LVAD may not be altered, these patients may experience greater morbidity and recurring infection. ${ }^{207}$ The most common VAD-specific infections are summarized in Table 2.

\section{STRATEGIES TO PROMOTE MYOCARDIAL RECOVERY}

Despite the wealth of functional and biologic evidence of reverse cardiac remodeling that occurs with mechanical unloading, few patients actually proceed to functional myocardial recovery, and even fewer to the point of having their LVAD explanted. Excluding patients with acute cardiogenic shock states requiring short-term mechanical support, LVAD-associated myocardial recovery is believed to occur in $<2 \%$ of all patients implanted with durable devices.

\section{Patient Selection}

Although the number of studies that have prospectively examined LVAD unloading and myocardial recovery are low, several specific recommendations can be offered. Patients with favorable characteristics are defined as age $<40$ years, nonischemic cardiomyopathies, and duration of heart failure $<5$ years. ${ }^{211}$ Device removal was more likely in younger patients (age $<40$ years) with nonischemic cardiomyopathy of short duration ( $<1$ year). In those who did undergo device explant, survival was $95 \%$ and $85 \%$ at 1 and 3 years, respectively. Freedom from recurrent heart failure requiring reimplantation or transplantation was $74 \%$ at 3.5 years. This study confirmed some of the previous characteristics seen in explanted patients that received pulsatile pumps. ${ }^{211}$ Birks and colleagues ${ }^{212,213}$ used intense medical therapy and vigilant surveillance thereby allowing LVAD explantation in 11 of $15(73 \%)$ patients with pulsatile LVADs and 12 of $20(60 \%)$ of patients with CF LVADs. Similarly, Dandel and colleagues ${ }^{214,215}$ explanted more than 100 patients with idiopathic dilated cardiomyopathy by using serial turndown echocardiograms to closely monitor changes in function and geometry to actively identify potential recovery candidates. The question remains whether or not a selective or global approach to aggressive efforts to resuscitate the failing myocardium should be encouraged. Although recognizing that certain patients are more likely to respond to LVAD unloading, should that exclude pursuing aggressive unloading and medical therapy for all patients receiving MCS? At least at this point, patients with favorable characteristics for recovery should be prospectively challenged with protocols to foster recovery.

\section{Adjuvant Therapies}

The Harefield protocol catalyzed interest in pharmacologic manipulation of the LVAD patient by early initiation of high-dose neurohormonal blockade. ${ }^{213}$ When the LV end diastolic diameter was $<6.0 \mathrm{~cm}$, carvedilol was replaced with selective beta 1-blockade and clenbuterol (beta 2-agonist) was added. At follow-up, patients who underwent LVAD removal for myocardial recovery demonstrated a durable recovery with good quality of life. ${ }^{215-217}$ This approach suggests that when an institution actively engages in intensive drug therapy and close monitoring of

TABLE 2. Ventricular assist device-specific infections ${ }^{208}$

\begin{tabular}{|c|c|}
\hline Site of infection & Distribution of organisms \\
\hline Driveline & $\begin{array}{l}\text { Staphylococcus aureus } 30 \%-44 \% \\
\text { Pseudomonas aeruginosa } 10 \%-28 \% \\
\text { Enteric gram-negative bacteria } 13 \%-30 \% \\
\text { Coagulase negative staphylococci } 7 \%-20 \% \\
\text { Enterococcus spp } 5 \%-15 \% \\
\text { Corynebacterium spp } 2 \%-15 \% \text { Candida spp } \\
\quad 0 \%-8 \%\end{array}$ \\
\hline Pocket & $\begin{array}{l}\text { Coagulase-negative staphylococci } 15 \% \text { - } \\
\quad 40 \% \\
\text { S aureus } 20 \%-30 \% \\
\text { Enterococcus spp } 20 \%-24 \% \\
\text { Enteric gram-negative bacteria } 5 \%-25 \% \\
\text { P aeruginosa } 5 \%-19 \% \\
\text { Candida spp } 10 \%\end{array}$ \\
\hline Pump/cannula & $\begin{array}{l}\text { Coagulase-negative staphylococci } 20 \% \text { - } \\
\quad 40 \% \\
\text { S aureus } 20 \% \\
\text { Paeruginosa } 8 \%-20 \% \text { Corynebacterium spp } \\
\quad 8 \%-20 \% \\
\text { Enteric gram-negative bacteria } 0 \%-15 \% \\
\text { Enterococcus spp } 0 \%-30 \%\end{array}$ \\
\hline
\end{tabular}




\begin{tabular}{lrr}
\hline & $\begin{array}{r}\text { Class of } \\
\text { Level of } \\
\text { evidence }\end{array}$ \\
\hline
\end{tabular}

Preoperative evaluation and optimization

1. Preoperative cardiac assessment for mechanical circulatory support should include:

a. An echocardiogram to evaluate valvular disease and intracardiac shunts.

b. Right heart catheterization to interrogate cardiac index, intra-cardiac filling pressures, and volume status.

c. A cardiopulmonary exercise test (if feasible) to objectively assess functional limitations and stratify risk

2. Assessment of right ventricular function should include physical examination, hepatic function studies,

echocardiography, and hemodynamics. Evidence for advanced right heart failure should prompt surgical planning for right ventricular support

3. Patients with ventricular dysrhythmias not responsive to hemodynamic optimization should undergo screening for ischemia

4. Patients with persistent ventricular dysrhythmias should be considered at high risk with isolated left ventricular support alone

5. Renal function assessed by blood urea nitrogen, serum creatinine, and estimate of glomerular filtration rate is recommended during the evaluation phase

6. Renal dysfunction is an important risk factor for adverse outcome with LVAD support and should be included in the estimate of postimplant mortality

7. Durable LVAD support as a bridge to transplant should not be considered in patients who are dialysis dependent unless they are also potential candidates for combined heart-kidney transplantation

8. Destination therapy is not advisable in patients who are dialysis dependent

9. Hepatic cirrhosis contraindicates LVAD implantation

10. Patients with moderate to severe obstructive or restrictive lung disease should undergo preoperative pulmonary function testing and pulmonary consultation. Clinically significant obstructive or restrictive lung disease may limit the functional benefits of LVAD therapy and should be considered a strong relative contraindication

11. Advanced idiopathic pulmonary fibrosis should be considered a contraindication for VAD implant

12. Patients with a history of cerebrovascular disease and/or previous stroke and those with a carotid artery bruit should undergo carotid duplex ultrasonography and possibly a baseline head CT scan or MRI

13. Patients with active systemic and/or localized infections should be considered at high risk for LVAD implant. Consideration should be given to delaying implantation until infection has resolved

14. Risk stratification for durable LVAD support should include determination of body mass index and serological measures of nutrition

15. Peripheral vascular disease should be evaluated before LVAD implant. Extensive atherosclerotic disease may preclude candidacy for LVAD support

16. Anemia, thrombocytopenia, and coagulation abnormalities should be evaluated before implant. Findings suggestive of a prothrombotic state should be considered a possible risk factor for pump thrombosis

17. Psychiatric disorders, substance abuse, history of noncompliance, lack of family or caregiver support, and lack of financial resources should be identified and addressed before LVAD implant

18. In patients with ischemic cardiomyopathy, imaging of the ascending aorta and arch can be used to evaluate for the presence of atherosclerotic disease that could increase the risk of embolization during cannulation and/or the outflow graft anastomosis

19. Preimplant hemodynamic optimization may reduce postoperative complications. The following strategies are recommended:

a. Elevated filling pressures should be treated by the use of intravenous loop diuretics. If severe and refractory, ultrafiltration or hemodialysis can be considered, but may increase the risk for post- LVAD renal dysfunction.

b. Low cardiac output state should be treated with Inotropic agents and, if persistent, an IABP

c. Caution should be exercised when using oral or inhaled pulmonary vasodilators to treat residual pulmonary hypertension, particularly in the setting of elevated left-sided filling pressures

Support techniques in cardiogenic shock

1. IABP support is recommended for cardiogenic shock complicating acute myocardial infarction, but additional mechanical support may be needed if prompt hemodynamic improvement is not forthcoming

2. Percutaneous LV to aorta pumps of appropriate size should be considered for cardiogenic shock from primary LV failure

$\begin{array}{cc}\text { I } & \text { C } \\ \text { I } & \text { B } \\ \text { I } & \text { A } \\ \text { I } & \text { B } \\ & \\ \text { IIa } & \text { C } \\ \text { IIa } & \text { C } \\ \text { I } & \text { B } \\ \text { I } & \text { B } \\ \text { IIb } & \text { C } \\ \text { III } & \\ \text { III } & \text { C } \\ \text { IIa } & \text { C }\end{array}$

$\begin{array}{cc}\text { III } & \text { C } \\ \text { I } & \text { C } \\ \text { I } & \text { C } \\ \text { I } & \text { B } \\ \text { IIa } & \text { C } \\ \text { IIa } & \text { C } \\ \text { I } & \text { C } \\ \text { I } & \text { C }\end{array}$

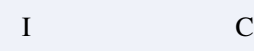

I C

IIb C 


\begin{tabular}{|c|c|c|}
\hline Recommendation & $\begin{array}{l}\text { Class of } \\
\text { recommendations }\end{array}$ & $\begin{array}{l}\text { Level of } \\
\text { evidence }\end{array}$ \\
\hline $\begin{array}{l}\text { 3. Percutaneous right ventricular assist device support should be considered for cardiogenic shock from primary } \\
\text { right ventricular failure }\end{array}$ & IIIa & B \\
\hline $\begin{array}{l}\text { 4. ECMO support can be considered for cardiogenic shock as a method of initial resuscitation for right, left, or } \\
\text { biventricular failure }\end{array}$ & IIa & B \\
\hline 5. ECMO with femoral artery cannulation should include placement of a distal femoral artery perfusion catheter & I & B \\
\hline \multicolumn{3}{|l|}{ Indications for biventricular support } \\
\hline $\begin{array}{l}\text { 1. The possibility of biventricular support should be included in the surgical plan if biventricular failure is } \\
\text { documented with } \mathrm{CI}<2.0 \mathrm{~L} / \mathrm{min} / \mathrm{m}^{2} \text {, right atrial pressure }>17 \mathrm{~mm} \mathrm{Hg} \text {, and CVP/PCWP ratio }>0.63\end{array}$ & IIa & $\mathrm{C}$ \\
\hline $\begin{array}{l}\text { 2. Patients who undergo placement of temporary MCS (percutaneous VAD or ECMO) should have right } \\
\text { ventricle function evaluated at regular intervals; if it remains poor and patient is a transplant candidate, } \\
\text { consideration for biventricular support or TAH is advisable }\end{array}$ & IIa & $\mathrm{C}$ \\
\hline $\begin{array}{l}\text { 3. Patients who received an LVAD as bridge to transplant and remain with poorly controlled right ventricular } \\
\text { failure (with or without a temporary right VAD) should be considered for longer-term biventricular support or } \\
\text { TAH before end-organ dysfunction ensues }\end{array}$ & IIa & $\mathrm{C}$ \\
\hline $\begin{array}{l}\text { 4. The use of biventricular support should be considered for patients who remain in refractory biventricular } \\
\text { failure or experience persistent destabilizing ventricular dysrhythmias, and have sufficient cavity size for the } \\
\text { inflow cannulas. TAH can also be considered in these populations and in patients with infiltrative-restrictive } \\
\text { cardiomyopathies, heart graft failure, thrombosed ventricles, and some cardiac tumors. }\end{array}$ & IIa & $\mathrm{C}$ \\
\hline \multicolumn{3}{|l|}{ Surgical approach } \\
\hline $\begin{array}{l}\text { 1. Intraoperative assessment of right ventricular function should include transesophageal echocardiography and } \\
\text { invasive monitoring using pulmonary artery catheter (when feasible) }\end{array}$ & I & B \\
\hline $\begin{array}{l}\text { 2. Successful LVAD implantation (regardless of incision) requires adequate positioning of the inflow and } \\
\text { outflow cannulas, LVAD pump, and driveline }\end{array}$ & I & B \\
\hline $\begin{array}{l}\text { 3. Measures to maintain appropriate intraoperative ventilator management, avoid hypovolemia/hypervolemia } \\
\text { and hypotension, maintain sinus rhythm, and judiciously optimize pump speed under transesophageal } \\
\text { echocardiography guidance should be included during LVAD implantation }\end{array}$ & I & $\mathrm{C}$ \\
\hline $\begin{array}{l}\text { 4. Treatment of coexisting valvular pathologies at the time of LVAD implant must be balanced against the } \\
\text { anticipated duration of support }\end{array}$ & I & B \\
\hline $\begin{array}{l}\text { 5. Greater than mild aortic insufficiency (assessed by echocardiography with appropriate afterload) should be } \\
\text { addressed with either valve closure, repair, or replacement }\end{array}$ & I & B \\
\hline $\begin{array}{l}\text { 6. A mechanical aortic valve prosthesis should either be replaced with a bioprosthesis or covered/closed with a } \\
\text { patch at the time of VAD implant }\end{array}$ & I & $\mathrm{C}$ \\
\hline 7. The presence of a patent foramen ovale mandates surgical closure & I & $\mathrm{C}$ \\
\hline $\begin{array}{l}\text { 8. Meticulous surgical techniques aimed toward avoiding right ventricular ischemia/distention and strategies to } \\
\text { minimize perioperative surgical bleeding, including selective delayed sternal closure, should be utilized } \\
\text { during LVAD implantation }\end{array}$ & IIa & $\mathrm{C}$ \\
\hline $\begin{array}{l}\text { 9. Appropriate pocket formation and positioning of the inflow cannula should be verified when the chest is } \\
\text { closed }\end{array}$ & I & $\mathrm{C}$ \\
\hline $\begin{array}{l}\text { 10. Early planned implantation of temporary right ventricular support should be considered in patients with } \\
\text { severe right ventricle dysfunction after LVAD implantation }\end{array}$ & I & $\mathrm{C}$ \\
\hline $\begin{array}{l}\text { 11. The driveline should course below the rectus and exit with buried velour and minimal devitalized tissue in the } \\
\text { path }\end{array}$ & I & B \\
\hline $\begin{array}{l}\text { 12. Pulmonary vasodilators (inhaled and systemic) should be considered perioperatively to reduce right ventricle } \\
\text { afterload (pulmonary artery pressures) }\end{array}$ & IIa & B \\
\hline $\begin{array}{l}\text { 13. Specific attention to the final pump body position, sewing ring access, and outflow path aids in device } \\
\text { exchange through less invasive reoperation when necessary }\end{array}$ & I & B \\
\hline $\begin{array}{l}\text { 14. The inflow cannula should be placed so that the cannula is parallel to the interventricular septum toward the } \\
\text { center of the left ventricular cavity and facing the mitral valve. This can be accomplished by placing the } \\
\text { HeartMate II, HeartMate } 3 \text { or HVAD inflow cannula through the true apex, approximately } 1 \mathrm{~cm} \text { above the } \\
\text { apex, or through the diaphragmatic surface near the apex }\end{array}$ & I & $\mathrm{C}$ \\
\hline $\begin{array}{l}\text { 15. Adequate size and depth of pump pocket is recommended for the HeartMate II to maintain the desired angle } \\
\text { and direction of the inflow cannula }\end{array}$ & I & $\mathrm{C}$ \\
\hline
\end{tabular}




\begin{tabular}{|c|c|c|}
\hline Recommendation & $\begin{array}{l}\text { Class of } \\
\text { recommendations }\end{array}$ & $\begin{array}{l}\text { Level of } \\
\text { evidence }\end{array}$ \\
\hline $\begin{array}{l}\text { 16. The outflow graft length should be selected to avoid both graft kinking (if too long) and right ventricular } \\
\text { compression by crossing the acute margin of the ventricle (if too short) }\end{array}$ & I & $\mathrm{C}$ \\
\hline \multicolumn{3}{|l|}{ Management of postoperative bleeding } \\
\hline $\begin{array}{l}\text { 1. Preoperative management optimizing hemodynamics and nutrition parameters, discontinuing anticoagulants } \\
\text { and antiplatelet medication, and meticulous LVAD focused surgical techniques all contribute to avoidance of } \\
\text { excessive postsurgical bleeding }\end{array}$ & I & $\mathrm{C}$ \\
\hline 2. Antifibrinolytics may decrease bleeding and transfusion requirements & IIa & $\mathrm{C}$ \\
\hline $\begin{array}{l}\text { 3. If coagulopathy cannot be reversed, mediastinal packing with delayed chest closure can be used successfully } \\
\text { without a higher incidence of infection }\end{array}$ & IIa & $\mathrm{C}$ \\
\hline \multicolumn{3}{|l|}{ Anticoagulation management } \\
\hline $\begin{array}{l}\text { 1. Initiation of anticoagulation and antiplatelet agents and international normalized ratio targets for } \\
\text { anticoagulant therapy should follow the Instructions for Use from the device manufacturer }\end{array}$ & I & B \\
\hline $\begin{array}{l}\text { 2. The safety and efficacy of nonvitamin } \mathrm{K} \text { antagonists for systemic anticoagulation in MCS patients has not } \\
\text { been established }\end{array}$ & III & $\mathrm{C}$ \\
\hline \multicolumn{3}{|l|}{ Optimizing pump speed } \\
\hline $\begin{array}{l}\text { 1. Pump speed should be adjusted to optimize hemodynamics in the early postoperative phase, but initial pump } \\
\text { speeds should be low enough to avoid leftward septal shift and induction of right ventricle dysfunction }\end{array}$ & IIa & $\mathrm{C}$ \\
\hline $\begin{array}{l}\text { 2. Surveillance echocardiographic assessment should be performed for changes in patient condition possibly } \\
\text { related to the degree of device unloading }\end{array}$ & IIa & $\mathrm{C}$ \\
\hline $\begin{array}{l}\text { 3. Right heart catheterization should be performed if heart failure, impaired end organ function, or significant } \\
\text { aortic insufficiency occurs; or following pulmonary hypertension reduction in a transplant candidate that } \\
\text { received LVAD due to high transpulmonary pressure gradient }\end{array}$ & IIa & $\mathrm{C}$ \\
\hline $\begin{array}{l}\text { 4. Decreasing pump speed to increase pulsatility may decrease the stimulus for arteriovenous malformations } \\
\text { and decrease the risk for gastrointestinal bleeding }\end{array}$ & $\mathrm{IIb}$ & $\mathrm{C}$ \\
\hline \multicolumn{3}{|l|}{ Diagnosis and management of pump malfunction } \\
\hline $\begin{array}{l}\text { 1. Diagnostic studies for suspected device malfunction should include clinical evaluation, laboratory testing } \\
\text { (serum blood urea nitrogen, creatinine, liver function tests, lactate, lactate dehyrogenase, lactate } \\
\text { dehydrogenase isoenzymes, plasma free hemoglobin, B-type natriuretic peptide levels, and urine analyzed } \\
\text { for hemoglobinuria), interrogation of pump alarms, cardiac imaging, chest radiograph, and in some instances } \\
\text { hemodynamic assessment should be performed }\end{array}$ & I & $\mathrm{C}$ \\
\hline $\begin{array}{l}\text { 2. A review of log files and/or ramp study that evaluates the interaction between pump power consumption, } \\
\text { pump speed, flow calculation, } \mathrm{LV} \text { dimensions, and aortic valve opening is recommended for patients in whom } \\
\text { continuous-flow VAD malfunction is suspected }\end{array}$ & I & B \\
\hline $\begin{array}{l}\text { 3. Detection of serum lactate dehydrogenase }>2.5 \text { times the upper limits of normal (based on specific isoforms } \\
\text { for hemolysis if available) or a plasma free hemoglobin }>40 \mathrm{mg} / \mathrm{dL} \text { after the first week is suggestive of pump } \\
\text { thrombus/thrombosis }\end{array}$ & IIa & B \\
\hline $\begin{array}{l}\text { 4. A transthoracic (or transesophageal) echocardiogram with Doppler or cine CT study should be obtained in } \\
\text { patients with suspected VAD malfunction to evaluate the positioning of the inflow cannula and ventricular } \\
\text { septum, the LV size, and the status of the native cardiac valves }\end{array}$ & I & B \\
\hline $\begin{array}{l}\text { 5. Three-dimensional contrast imaging or CT angiography should be considered to evaluate for graft obstruction } \\
\text { and/or pump malposition }\end{array}$ & I & B \\
\hline $\begin{array}{l}\text { 6. Hemodynamic evaluation with a pulmonary artery catheter may be useful in selected patients to diagnose } \\
\text { VAD malfunction }\end{array}$ & I & $\mathrm{C}$ \\
\hline $\begin{array}{l}\text { 7. Patients should be screened at regular intervals for evidence of hemolysis as an indicator of pump thrombosis. } \\
\text { Screening includes clinic visits, laboratory studies, review of pump parameters, and imaging }\end{array}$ & I & B \\
\hline $\begin{array}{l}\text { 8. Patients with suspected LVAD thrombosis should be urgently transferred to a quaternary care center with } \\
\text { expertise in mechanical circulatory support }\end{array}$ & I & $\mathrm{C}$ \\
\hline $\begin{array}{l}\text { 9. In case of hemodynamic instability, patients should be transferred to an intensive care unit for close } \\
\text { monitoring and initiation of therapy with anticoagulation and heart failure medications. Preparation for pump } \\
\text { exchange usually includes therapy with inotropes and diuresis }\end{array}$ & I & $\mathrm{C}$ \\
\hline $\begin{array}{l}\text { 10. Resolution of clinical findings (power spikes, hemolysis, and/or heart failure) can be followed by uptitration } \\
\text { of antithrombotic therapy with ASA ( } 325 \mathrm{mg} \text { ) and anticoagulant to an international normalized ratio target of } \\
\text { 2.5-3.0. Uptitration of antithrombotic therapy must be guided by the patient's coexistent comorbidities and }\end{array}$ & I & $\mathrm{C}$ \\
\hline
\end{tabular}




\begin{tabular}{|c|c|c|}
\hline Recommendation & $\begin{array}{l}\text { Class of } \\
\text { recommendations }\end{array}$ & $\begin{array}{l}\text { Level of } \\
\text { evidence }\end{array}$ \\
\hline \multicolumn{3}{|l|}{$\begin{array}{l}\text { potential risks of bleeding. Consideration can be given to the addition of a second antiplatelet agent (eg, } \\
\text { clopidogrel or dipyridamole) }\end{array}$} \\
\hline $\begin{array}{l}\text { 11. Short-term anticoagulation with platelet glycoprotein IIb/IIIa receptor inhibition may be considered as part of } \\
\text { conservative treatment of VAD thrombosis or used as a bridge to a longer-term strategy, including VAD } \\
\text { exchange or cardiac transplantation }\end{array}$ & IIa & B \\
\hline $\begin{array}{l}\text { 12. Intravenous or intraventricular thrombolysis should be used with extreme caution because of the risk of severe } \\
\text { bleeding complications, but can be considered if the patient is not a surgical candidate }\end{array}$ & $\mathrm{IIb}$ & B \\
\hline $\begin{array}{l}\text { 13. If hemolysis persists despite aggressive antithrombotic therapy, consideration should be given to pump } \\
\text { exchange if the patient is deemed a surgical candidate }\end{array}$ & I & $\mathrm{C}$ \\
\hline $\begin{array}{l}\text { 14. Urgent transplantation can be pursued if the estimated waiting time is short, the patient does not have } \\
\text { unmanageable heart failure symptoms, the end-organ function is preserved, and the patient is otherwise a } \\
\text { good candidate }\end{array}$ & I & $\mathrm{C}$ \\
\hline $\begin{array}{l}\text { 15. Among patients undergoing pump exchange for suspected pump thrombosis, an operative approach should be } \\
\text { selected after determination of the extent/location of thrombosis with appropriate imaging }\end{array}$ & IIa & $\mathrm{C}$ \\
\hline $\begin{array}{l}\text { 16. Weaning and device explantation is the therapy of choice for patients with pump thrombosis and recovery of } \\
\text { ventricular function }\end{array}$ & I & $\mathrm{C}$ \\
\hline \multicolumn{3}{|l|}{ Management of pump-related infections } \\
\hline $\begin{array}{l}\text { 1. Patients should receive preoperative antibiotics with broad-spectrum gram-positive and gram-negative } \\
\text { coverage as appropriate. Routine antibiotic prophylaxis should include at least } 1 \text { dose before surgery } \\
\text { administered within } 60 \mathrm{~min} \text { of the first incision, remain in the therapeutic range throughout the duration of } \\
\text { their use, and not extend beyond } 48 \mathrm{~h}\end{array}$ & I & $\mathrm{C}$ \\
\hline $\begin{array}{l}\text { 2. Patients should have a nasal swab to screen for methicillin resistant Staphylococcus aureus and receive topical } \\
\text { treatment if positive }\end{array}$ & IIa & $\mathrm{C}$ \\
\hline $\begin{array}{l}\text { 3. Patients with active infection should receive appropriate targeted antibiotic/antifungal therapy and optimally } \\
\text { postpone the procedure until it resolves }\end{array}$ & I & $\mathrm{C}$ \\
\hline 4. Antifungal prophylaxis should be considered based on individual site colonization & IIa & $\mathrm{C}$ \\
\hline $\begin{array}{l}\text { 5. Externalization of only the silicon portion of the driveline is recommended. The velour-covered portion of the } \\
\text { driveline should be buried } \sim 3-5 \mathrm{~cm} \text { below the skin surface }\end{array}$ & I & B \\
\hline $\begin{array}{l}\text { 6. Double tunnel technique should be considered to maximize pump to exit site distance and to better distribute } \\
\text { tension on the driveline in case of weight change }\end{array}$ & IIa & $\mathrm{C}$ \\
\hline $\begin{array}{l}\text { 7. The driveline should be externally stabilized immediately after the implant and throughout the duration of } \\
\text { support }\end{array}$ & I & $\mathrm{C}$ \\
\hline $\begin{array}{l}\text { 8. Suspected driveline or pump pocket infection should be investigated with microbial cultures, white blood cell } \\
\text { count, and pump pocket/driveline imaging studies }\end{array}$ & IIa & $\mathrm{C}$ \\
\hline $\begin{array}{l}\text { 9. Methods for treating infections of the driveline exit site include systemic and local antimicrobial therapy, } \\
\text { local wound care, and surgical debridement }\end{array}$ & IIa & B \\
\hline $\begin{array}{l}\text { 10. Deep driveline infections should be managed with parenteral antibiotics, surgical drainage with or without } \\
\text { antibiotic bead placement, and/or use of negative pressure healing devices. In selected cases, pump exchange } \\
\text { with relocation of the driveline has proven effective }\end{array}$ & IIa & $\mathrm{C}$ \\
\hline $\begin{array}{l}\text { 11. In case of proven pump pocket infection, a re-exploration is indicated. After debridement and irrigation of } \\
\text { infected pump pocket, negative pressure wound therapy combined with systemic targeted antibiotics is } \\
\text { recommended until the pump pocket becomes reasonably clean and the cultures negative }\end{array}$ & I & $\mathrm{C}$ \\
\hline $\begin{array}{l}\text { 12. Infection of the mediastinum in a VAD patient requires surgical intervention to decrease the burden of } \\
\text { microorganisms to the greatest extent possible. Recommended methods to achieve this include device } \\
\text { removal with cardiac transplantation, pump replacement, and the use of antibiotic eluting beads with or } \\
\text { without adjunctive omental coverage }\end{array}$ & I & $\mathrm{C}$ \\
\hline $\begin{array}{l}\text { 13. If the pump is internally infected (device endocarditis) with persistent positive blood cultures, one should } \\
\text { assume complete system contamination. In these cases, consideration should be given to replacing the entire } \\
\text { system }\end{array}$ & IIa & $\mathrm{C}$ \\
\hline $\begin{array}{l}\text { 14. For patients listed for transplantation with VAD- (or TAH) associated infection, transplantation is generally } \\
\text { safe after debridement and drainage of infected collections, appropriate duration of antibiotics tailored to } \\
\text { specific organism (with guidance from infectious disease experts), and resolution of bacteremia. Removal of } \\
\text { the contaminated VAD system usually enables eradication of infection }\end{array}$ & I & $\mathrm{C}$ \\
\hline
\end{tabular}




\begin{tabular}{|c|c|c|}
\hline Recommendation & $\begin{array}{c}\text { Class of } \\
\text { recommendations }\end{array}$ & $\begin{array}{l}\text { Level of } \\
\text { evidence }\end{array}$ \\
\hline $\begin{array}{l}\text { 15. After transplantation and removal of infected LVAD (or TAH), extensive irrigation with antibiotic solution at } \\
\text { time of transplant and prolonged drainage is useful to prevent recurring mediastinal infection }\end{array}$ & IIa & $\mathrm{C}$ \\
\hline \multicolumn{3}{|l|}{$\begin{array}{l}\text { 1. LVAD patients with favorable characteristics for recovery (age }<40 \mathrm{y} \text {, nonischemic cardiomyopathies, } \\
\text { duration of heart failure }<5 \mathrm{y} \text { ) should receive optimal mechanical unloading and standard heart failure } \\
\text { drugs at the highest tolerated doses to promote reverse remodeling and myocardial recovery with the } \\
\text { following considerations: }\end{array}$} \\
\hline $\begin{array}{l}\text { a. Optimize LVAD speed to balance adequate cardiac output, right ventricular function, and maximal left } \\
\text { ventricle decompression }\end{array}$ & IIa & B \\
\hline $\begin{array}{l}\text { b. Biweekly uptitration of neurohormonal antagonists, including renin-angiotensin-aldosterone and beta } \\
\text { receptor blockers }\end{array}$ & IIa & B \\
\hline $\begin{array}{l}\text { 2. All LVAD patients should receive optimal mechanical unloading and standard heart failure drugs at the } \\
\text { highest tolerated doses to promote reverse remodeling and myocardial recovery }\end{array}$ & IIa & $\mathrm{C}$ \\
\hline $\begin{array}{l}\text { 3. LVAD patients with favorable characteristics should be evaluated with protocol-driven turn down } \\
\text { echocardiography bimonthly for the first } 6 \text { mo (ie, screening phase) to assess the potential of myocardial } \\
\text { recovery }\end{array}$ & IIa & B \\
\hline $\begin{array}{l}\text { 4. LVAD patients demonstrating evidence of significant reverse remodeling and return of contractile function } \\
\text { should proceed to turndown invasive hemodynamic and cardiopulmonary functional testing for consideration } \\
\text { of LVAD explantation }\end{array}$ & IIa & B \\
\hline
\end{tabular}

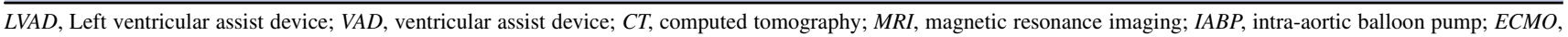
extracorporeal membrane oxygenation; $C I$, cardiac index; $C V P$, central venous pressure; $P C W P$, pulmonary capillary wedge pressure; $M C S$; mechanical circulatory support; $T A H$, total artificial heart; $A S A$, acetylsalicylic acid.

heart function, return of LV function may be diagnosed in a larger proportion of patients. ${ }^{218-220}$ The aggressive phase I portion of the Harefield protocol was investigated in the multicenter Remission From Stage D Heart Failure (RESTAGE) trial, and preliminary results suggest higher rates of explantation/remission among several centers. ${ }^{221,222}$

The phase II portion of the Harefield protocol was designed on the basis of data derived from animal models of heterotopic transplantation demonstrating that mechanical unloading of the normal, nonhypertrophic heart resulted in atrophy. However, a recent study provided structural, ultrastructural, microstructural, metabolic, molecular, and functional data indicating that prolonged CF LVAD unloading (which is partial compared with the full unloading induced by heterotopic transplant) does not induce hypertrophy regression to the point of atrophy and degeneration. ${ }^{222}$

Given that abrogating atrophy does not appear to be a target for adjuvant biologic therapies, intensive investigations are underway in an effort to identify other therapeutic targets to enhance reverse remodeling and augment contractile function. To date, reports are only at the pilot trial level and offer no insight as to their clinical efficacy. Individual centers have injected both autologous and allogeneic mesenchymal stem cells in patients with an LVAD. In addition, the National Institutes of Health-sponsored Cardiothoracic Surgery Network recently reported a 30-patient pilot trial of intramyocardial mesenchymal stem cell injection at the time of LVAD placement. ${ }^{23,224}$ There were no safety issues and potential efficacy signals were observed. A subsequent trial from the Cardiothoracic Surgery Network has successfully recruited 159 patients from 19 centers with follow-up in progress.

\section{Surgical Approaches}

Although variability of clinical presentation will often determine the specifics for surgical implantation, prospectively setting the goal of recovery implies the need to fix structural heart defects at the time of the initial implant. Fundamentally, a surgical team has to ask, How will the heart work when the pump is removed? The most common scenario is related to valve disorders, and much has been written about management of concomitant valve disease with patients requiring VAD. ${ }^{91,225}$ To promote myocardial recovery, surgical approaches should aim to fix correctable lesions, including coronary revascularization. Some technical details are obvious (eg, not oversewing an aortic valve for aortic insufficiency), whereas others appear controversial (eg, mitral repair for mitral regurgitation). Multiple methods for LVAD explantation for the recovery patient have been described and recently reviewed. ${ }^{226}$

\section{Weaning Protocols}

Part of the confusion within the field is the definition of recovery. Reverse remodeling is necessary, but not always sufficient for true recovery. Conversely, myocardial architecture and gene expression can remain altered, but the 
contractile function might dramatically increase. To be clinically relevant, myocardial recovery after mechanical unloading must imply the possibility of removing the LVAD. In general, a heart that has decreased in size (LV end diastolic diameter $<6 \mathrm{~cm}$ ) and has regained contractile function (LV ejection fraction $>40 \%$ ) during a turndown or turn-off LVAD study is a responder to unloading and potentially a candidate for LVAD explantation.

Although several groups have published their experience with VAD weaning, no universal weaning protocol exists. As mentioned, the approaches described by Birks and colleagues and Dandel and colleagues ${ }^{213-215,227}$ are the most studied and include serial echocardiography to assess unloading and return of function. Frazier and colleagues ${ }^{228}$ championed a strategy based on the cardiac cycle. When adequately unloaded (eg, normal LV dimensions and minimal mitral regurgitation), patients are serially evaluated at minimal pump speeds for normalization of aortic valve opening time. With this reconditioning approach, they have removed pumps from more than 30 patients. ${ }^{228}$

Formica and colleagues ${ }^{229}$ use a 3-step approach. After achieving maximally tolerated doses of heart failure medicines and if turndown echocardiography demonstrated an LV ejection fraction $>40 \%$ (step 1), they then proceed to cardiopulmonary stress test (step 2), and right heart catheterization (step 3). Of 34 patients, 21 subjects made it to step 1 testing, with 16 showing no evidence of improved function. Of the remaining 5 who achieved normalized function: 1 elected to keep the LVAD, 1 had an exerciseinduced increase in pulmonary capillary wedge pressure and was not deemed an explant candidate, and 3 went on to explantation and are free from major heart failure events 3 to 5 years after explant. ${ }^{219}$

Turndown (or pump-off) testing is viewed as an important feature of all protocols. It is included in all testing and is an important component for determining candidacy for explant. Turndown testing with arguable criteria for device removal include echocardiography (LV ejection fraction $>40 \%-50 \%$, LV end diastolic diameter $<5.5-6.0 \mathrm{~cm}$, and LV end systolic diameter $<4.5-5.0 \mathrm{~cm}$ ), right heart catheterization (pulmonary capillary wedge pressure $<15 \mathrm{~mm}$ $\mathrm{Hg}$ and cardiac index $>2.2 \mathrm{~L} / \mathrm{min} / \mathrm{m}^{2}$ ), and cardiopulmonary exercise test $>16 \mathrm{~mL} / \mathrm{kg} / \mathrm{min}$ and ventilation-tocarbon dioxide output slope $<35$. $^{226}$

\section{LIMITATIONS}

The guidelines recommendations are summarized in Table 3. Given the experiential nature of complex surgical specialties like MCS, few aspects of standard practice are supported by randomized clinical trials. Of necessity, a majority of the guidelines included in this document are Level of Evidence C. Readers should realize that the cited recommendations are a hybrid product of true evidence-based guidelines and expert consensus opinion coupled with a review of the literature. Strict application of these recommendations to practice must be tempered by local circumstances and experience.

\section{Conflict of Interest Statement}

Relationships with industry and other relevant entities for guideline editors, contributing authors, and reviewers are listed in Appendix 1.

\section{References}

1. Rose EA, Gelijns AC, Moskowitz AJ, Heitjan DF, Stevenson LW, Dembitsky W, et al. Long-term use of a left ventricular assist device for end-stage heart failure. N Engl J Med. 2001;345:1435-43.

2. Kirklin JK, Pagani FD, Kormos RL, Stevenson LW, Blume ED, Myers SL, et al Eighth annual INTERMACS report: special focus on framing the impact of adverse events. J Heart Lung Transplant. 2017;36:1080-6.

3. Svensson LG, Gillinov AM, Weisel RD, Keshavjee S, Bacha EA, Moon MR, et al. The American Association for Thoracic Surgery consensus guidelines: reasons and purpose. J Thorac Cardiovasc Surg. 2016;151:935-9.

4. Bakaeen FG, Svensson LG, Mitchell JD, Keshavjee S, Patterson GA, Weisel RD. The American Association for Thoracic Surgery/Society of Thoracic Surgeons position statement on developing clinical practice documents. J Thorac Cardiovasc Surg. 2017;153:999-1005.

5. Levy WC, Mozaffarian D, Linker DT, Sutradhar SC, Anker SD, Cropp AB, et al. The Seattle Heart Failure Model: prediction of survival in heart failure. Circulation. 2006;113:1424-33.

6. Aaronson KD, Schwartz JS, Chen TM, Wong KL, Goin JE, Mancini DM Development and prospective validation of a clinical index to predict survival in ambulatory patients referred for cardiac transplant evaluation. Circulation. 1997;95:2660-7.

7. Stevenson LW, Pagani FD, Young JB, Jessup M, Miller L, Kormos RL, et al. INTERMACS profiles of advanced heart failure: the current picture. J Heart Lung Transplant. 2009;28:535-41.

8. Lietz K, Long JW, Kfoury AG, Slaughter MS, Silver MA, Milano CA, et al. Outcomes of left ventricular assist device implantation as destination therapy in the post-REMATCH era: implications for patient selection. Circulation. 2007;116: 497-505.

9. Cowger J, Sundareswaran K, Rogers JG, Park SJ, Pagani FD, Bhat G, et al. Predicting survival in patients receiving continuous flow left ventricular assist devices: the HeartMate II risk score. J Am Coll Cardiol. 2013;61:313-21.

10. Estep JD, Starling RC, Horstmanshof DA, Milano CA, Selzman CH, Shah KB et al. Risk assessment and comparative effectiveness of left ventricular assist device and medical management in ambulatory heart failure patients: results from the ROADMAP study. J Am Coll Cardiol. 2015;66:1747-61.

11. Fitzpatrick JR III, Frederick JR, Hsu VM, Kozin ED, O’Hara ML, Howell E, et al. Risk score derived from pre-operative data analysis predicts the need for biventricular mechanical circulatory support. J Heart Lung Transplant. 2008;27:1286-92.

12. Matthews JC, Koelling TM, Pagani FD, Aaronson KD. The right ventricular failure risk score: a pre-operative tool for assessing the risk of right ventricular failure in left ventricular assist device candidates. J Am Coll Cardiol. 2008;51: 2163-72.

13. Aissaoui N, Salem JE, Paluszkiewicz L, Morshuis M, Guerot E, Gorria GM, et al. Assessment of right ventricular dysfunction predictors before the implantation of a left ventricular assist device in end-stage heart failure patients using echocardiographic measures (ARVADE): combination of left and right ventricular echocardiographic variables. Arch Cardiovasc Dis. 2015;108:300-9.

14. Drakos SG, Janicki L, Horne BD, Kfoury AG, Reid BB, Clayson S, et al. Risk factors predictive of right ventricular failure after left ventricular assist device implantation. Am J Cardiol. 2010;105:1030-5.

15. Raina A, Rammohan HR, Gertz ZM, Rame JE, Woo YJ, Kirkpatrick JN. Postoperative right ventricular failure after left ventricular assist device placement is predicted by preoperative echocardiographic structural, hemodynamic, and functional parameters. J Card Fail. 2013;19:16-24. 
16. Atluri P, Goldstone AB, Fairman AS, MacArthur JW, Shudo Y, Cohen JE, et al. Predicting right ventricular failure in the modern, continuous flow left ventricular assist device era. Ann Thorac Surg. 2013;96:857-64.

17. Kormos RL, Teuteberg JJ, Pagani FD, Russell SD, John R, Miller LW, et al. Right ventricular failure in patients with the HeartMate II continuous-flow left ventricular assist device: incidence, risk factors, and effect on outcomes. J Thorac Cardiovasc Surg. 2010;139:1316-24.

18. Fitzpatrick JR III, Frederick JR, Hiesinger W, Hsu VM, McCormick RC Kozin ED, et al. Early planned institution of biventricular mechanical circulatory support results in improved outcomes compared with delayed conversion of a left ventricular assist device to a biventricular assist device. J Thorac Cardiovasc Surg. 2009;137:971-7.

19. Morgan JA, John R, Lee BJ, Oz MC, Naka Y. Is severe right ventricular failure in left ventricular assist device recipients a risk factor for unsuccessful bridging to transplant and post-transplant mortality. Ann Thorac Surg. 2004;77:859-63.

20. Shirazi JT, Lopshire JC, Gradus-Pizlo I, Hadi MA, Wozniak TC, Malik AS Ventricular arrhythmias in patients with implanted ventricular assist devices: a contemporary review. Europace. 2013;15:11-7.

21. Farrar DJ. Preoperative predictors of survival in patients with Thoratec ventricular assist devices as a bridge to heart transplantation. Thoratec Ventricular Assist Device Principal Investigators. J Heart Lung Transplant. 1994;13(1 Pt 1):93-100.

22. Sandner SE, Zimpfer D, Zrunek P, Rajek A, Schima H, Dunkler D, et al. Renal function and outcome after continuous flow left ventricular assist device implantation. Ann Thorac Surg. 2009;87:1072-8.

23. Ma L, Fujino Y, Matsumiya G, Sawa Y, Mashimo T. Renal function with left ventricular assist devices: the poorer the preoperative renal function, the longer the recovery. Med Sci Monit. 2008;14:CR621-7.

24. Butler J, Geisberg C, Howser R, Portner PM, Rogers JG, Deng MC, et al. Relationship between renal function and left ventricular assist device use. Ann Thorac Surg. 2006;81:1745-51.

25. Alba AC, Rao V, Ivanov J, Ross HJ, Delgado DH. Predictors of acute renal dysfunction after ventricular assist device placement. J Card Fail. 2009;15: 874-81.

26. Klotz S, Vahlhaus C, Riehl C, Reitz C, Sindermann JR, Scheld HH. Pre-operative prediction of post-VAD implant mortality using easily accessible clinical parameters. J Heart Lung Transplant. 2010;29:45-52.

27. Dell'Aquila AM, Avramovic N, Mastrobuoni S, Motekallemi A, Wisniewski K, Scherer M, et al. Fluorine-18 fluorodeoxyglucose positron emission tomography/computed tomography for improving diagnosis of infection in patients on CF-LVAD: longing for more 'insights'. Eur Heart J Cardiovasc Imaging. 2017; 19:532-43.

28. Brisco MA, Kimmel SE, Coca SG, Putt ME, Jessup M, Tang WW, et al. Prevalence and prognostic importance of changes in renal function after mechanical circulatory support. Circ Heart Fail. 2014;7:68-75.

29. Raichlin E, Baibhav B, Lowes BD, Zolty R, Lyden ER, Vongooru HR, et al. Outcomes in patients with severe preexisting renal dysfunction after continuous-flow left ventricular assist device implantation. ASAIO J. 2016;62:261-7.

30. Loghmanpour NA, Kanwar MK, Druzdzel MJ, Benza RL, Murali S, Antaki JF. A new Bayesian network-based risk stratification model for prediction of shortterm and long-term LVAD mortality. ASAIO J. 2015;61:313.

31. Holley G, Harvey L, Roy S, Cogswell R, Eckman P, Liao K, et al. Gastrointestinal bleeding during continuous flow left ventricular assist device support is associated with lower rates of cardiac transplantation. ASAIO J. 2015;61:635-9.

32. Goldstein DJ, Aaronson KD, Tatooles AJ, Silvestry SC, Jeevanandam V, Gordon R, et al. Gastrointestinal bleeding in recipients of the HeartWare ventricular assist system. JACC Heart Fail. 2015;3:303-13.

33. Draper KV, Huang RT, Gerson LB. Gastrointestinal bleeding in patients with continuous flow left ventricular assist devices: a systematic review and metaanalysis. Gastrointest Endosc. 2014;80:435-46.

34. Reinhartz O, Farrar OJ, Hershon JH, Avery GJ Jr, Haeusslein EA, Hill JD Importance of preoperative liver function as a predictor of survival in patients supported with Thoratec ventricular assist devices as a bridge to transplantation. J Thorac Cardiovasc Surg. 1998;116:633-40.

35. Yang JA, Kato TS, Shulman BP, Takayama H, Farr M, Jorde UP, et al. Liver dysfunction as a predictor of outcomes in patients with advanced heart failure requiring ventricular assist device support: use of the Model of End-stage Liver Disease (MELD) and MELD eXcluding INR (MELD-XI) scoring system. $J$ Heart Lung Transplant. 2012;31:601-10.

36. Bisdas T, Beutel G, Warnecke G, Hoeper MM, Kuehn C, Haverich A, et al. Vascular complications in patients undergoing femoral cannulation for extracorporeal membrane oxygenation support. Ann Thorac Surg. 2011;92: 626-31.

37. Gross TJ, Hunninghake GW. Idiopathic pulmonary fibrosis. $N$ Engl J Med. $2001: 345: 517-25$.

38. Holdy K, Dembitsky W, Eaton LL, Chillcott S, Stahovich M, Rasmusson, et al Nutrition assessment and management of left ventricular assist device patients. J Heart Lung Transplant. 2005;24:1690-6.

39. Lockard KL, Degore L, Schwarm P, Winowich S, O'Shea G, Siegenthaler M, et al. Lack of improvement in prealbumin at two weeks predicts poor outcome after mechanical circulatory support. J Heart Lung Transplant. 2009;28:S66.

40. Mano A, Fujita K, Uenomachi K, Kazama K, Katabuchi M, Wada K, et al. Body mass index is a useful predictor of prognosis after left ventricular assist system implantation. J Heart Lung Transplant. 2009;28:428-33.

41. Mohamedali B, Yost G, Bhat G. Obesity as a risk factor for consideration for left ventricular assist devices. J Card Fail. 2015:21:800-5.

42. Coyle LA, Ising MS, Gallagher C, Bhat G, Kurien S, Sobieski MA, et al. Destination therapy: one year outcomes in patients with a body mass index greater than. Artif Organs. 2010;34:93-7.

43. Butler J, Howser R, Portner P, Pierson RN. Body mass index and outcomes after left ventricular assist device placement. Ann Thorac Surg. 2005;79:66-73.

44. Yanagida R, Czer LS, Mirocha J, Rafiei M, Esmailian F, Moriguchi J, et al. Left ventricular assist device in patients with body mass index greater than 30 as bridge to weight loss and heart transplant candidacy. Transplant Proc. 2014; 46:3575-9.

45. Emani S, Brewer RJ, John R, Slaughter MS, Lanfear DE, Ravi Y, et al. Patients with low compared with high body mass index gain more weight after implantation of a continuous flow left ventricular assist device. J Heart Lung Transplant. 2013:32:31-5.

46. Spaderna H, Hellwig S, Schäfer T, Wagner FM, Smits JM, Weidner G. Depression and social isolation at time of wait listing reduce survival up to 5 years after heart transplantation-results from the waiting for a new heart study. J Heart Lung Transplant. 2014;33:S126.

47. Bruce CR, Delgado E, Kostick K, Grogan S, Ashrith G, Trachtenberg B, et al. Ventricular assist devices: a review of psychosocial risk factors and their impact on outcomes. J Card Fail. 2014;20:996-1003.

48. Kirklin JK, Naftel DC, Pagani FD, Kormos RL, Stevenson LW, Blume ED, et al. Sixth INTERMACS annual report: a 10,000-patient database. J Heart Lung Transplant. 2014;33:555-64.

49. Nohria A, Lewis E, Stevenson LW. Medical management of advanced heart failure. JAMA. 2002;287:628-40.

50. Berry W, McKenzie C. Use of inotropes in critical care. Clin Pharmacist. 2010; 2:395.

51. Unverzagt S, Wachsmuth L, Hirsch K, Thiele H, Buerke M, Haerting J, et al. Inotropic agents and vasodilator strategies for acute myocardial infarction complicated by cardiogenic shock or low cardiac output syndrome. Cochrane Database Syst Rev. 2014;1:CD009669.

52. Houston BA, Kalathiya RJ, Stevens GR, Russell SD, Tedford RJ. One-anddone: do left ventricular assist device patients on the transplant list really need frequent right heart catheterization assessments for pulmonary hypertension? J Heart Lung Transplant. 2015;34:1637-9.

53. Imamura T, Kinugawa K, Hatano M, Kato N, Minatsuki S, Muraoka H, et al. Acute pulmonary vasoreactivity test with sildenafil or nitric monoxide before left ventricular assist device implantation. J Artif Organs. 2013;16:389-92.

54. Cheng JM, den Uil CA, Hoeks SE, van der Ent M, Jewbali LS, van Domburg RT, et al. Percutaneous left ventricular assist devices vs. intra-aortic balloon pump counterpulsation for treatment of cardiogenic shock: a meta-analysis of controlled trials. Eur Heart J. 2009;30:2102-8.

55. Russo MJ, Jeevanandam V, Hur MJ, Johnson EM, Siffring T, Shah AP, et al. Prophylactic subclavian artery intraaortic balloon counter-pulsation is safe in highrisk cardiac surgery patients. ASAIO J. 2015;61:e36-9.

56. Thiele H, Zeymer U, Neumann FJ, Ferenc M, Olbrich HG, Hausleiter J, et al. Intraaortic balloon support for myocardial infarction with cardiogenic shock. N Engl J Med. 2012;367:1287-96.

57. Thiele H, Zeymer U, Neumann FJ, Ferenc M, Olbrich HG, Hausleiter J, et al. Intra-aortic balloon counter pulsation in acute myocardial infarction complicated by cardiogenic shock (IABP-SHOCK II): final 12-month results of a randomised, open-label trial. Lancet. 2013;382:1638-45.

58. Unverzagt S, Buerke M, de Waha A, Haerting J, Pietzner D, Seyfarth M, et al. Intra-aortic balloon pump counterpulsation (IABP) for myocardial infarction complicated by cardiogenic shock. Cochrane Database Syst Rev. 2015;3: CD007398. 
59. Zeymer U, Bauer T, Hamm C, Zahn R, Weidinger F, Seabra-Gomes R, et al. Use and impact of intra-aortic balloon pump on mortality in patients with acute myocardial infarction complicated by cardiogenic shock: results of the Euro Heart Survey on PCI. EuroIntervention. 2011;7:437-41.

60. Lemaire A, Anderson MB, Lee LY, Scholz P, Prendergast T, Goodman A, et al. The Impella device for acute mechanical circulatory support in patients in cardiogenic shock. Ann Thorac Surg. 2014;97:133-8.

61. Takayama H, Truby L, Koekort M, Uriel N, Colombo P, Mancini DM, et al. Clinical outcome of mechanical circulatory support for refractory cardiogenic shock in the current era. J Heart Lung Transplant. 2013;32:106-11.

62. Schibilsky D, Lausberg H, Haller C, Lenglinger M, Woernle B, Haeberle H, et al. Impella 5.0 support in INTERMACS II cardiogenic shock patients using right and left axillary artery access. Artif Organs. 2015;39:660-3.

63. Burkhoff D, Cohen H, Brunckhorst C, O'Neill WW. A randomized multicenter clinical study to evaluate the safety and efficacy of the TandemHeart percutaneous ventricular assist device versus conventional therapy with intraaortic balloon pumping for treatment of cardiogenic shock. Am Heart J. 2006;152: 469.e1-e8.

64. Seyfarth M, Sibbing D, Bauer I, Fröhlich G, Bott-Flügel L, Byrne R, et al. A randomized clinical trial to evaluate the safety and efficacy of a percutaneous left ventricular assist device versus intra-aortic balloon pumping for treatment of cardiogenic shock caused by myocardial infarction. J Am Coll Cardiol. 2008;52:1584-8.

65. Lauten A, Engström AE, Jung C, Empen K, Erne P, Cook S, et al. Response to letter regarding article, "Percutaneous left-ventricular support with the Impella2.5 assist device in acute cardiogenic shock results of the ImpellaEUROSHOCK registry". Circ Heart Fail. 2013;6:e56.

66. Batsides G, Massaro J, Cheung A, Soltesz E, Ramzy D, Anderson MB. Outcomes of Impella 5.0 in cardiogenic shock: a systematic review and meta-analysis. Innovations (Phila). 2018;13:254-60.

67. Gilotra NA, Stevens GR. Temporary mechanical circulatory support: a review of the options, indications, and outcomes. Clin Med Insights Card. 2015; 8(Suppl 1):75-85.

68. Cheng R, Hachamovitch R, Kittleson M, Patel J, Arabia F, Moriguchi J. Complications of extracorporeal membrane oxygenation for treatment of cardiogenic shock and cardiac arrest: a meta-analysis of 1,866 adult patients. Ann Thorac Surg. 2014;97:610-6.

69. Xie A, Phan K, Tsai MY, Yan TD, Forrest P. Venoarterial extracorporeal membrane oxygenation for cardiogenic shock and cardiac arrest: a meta-analysis. $J$ Cardiothorac Vasc Anesth. 2015;29:637-45.

70. MacLaren G, Butt W, Best D, Donath S. Central extracorporeal membrane oxygenation for refractory pediatric septic shock. Pediatr Crit Care Med. 2011;12:133-6.

71. Boulate D, Luyt CE, Pozzi M, Niculescu M, Combes A, Leprince P, et al. Acute lung injury after mechanical circulatory support implantation in patients on extracorporeal life support: an unrecognized problem. Eur J Cardiothorac Surg. 2013;44:544-9.

72. Chen YS, Lin JW, Yu HY, Ko WJ, Jerng JS, Chang WT, et al. Cardiopulmonary resuscitation with assisted extracorporeal life-support versus conventional cardiopulmonary resuscitation in adults with in-hospital cardiac arrest: an observational study and propensity analysis. Lancet. 2008;372:554-61.

73. Leick J, Liebetrau C, Szardien S, Fischer-Rasokat U, Willmer M, van Linden A, et al. Door-to-implantation time of extracorporeal life support systems predicts mortality in patients with out-of-hospital cardiac arrest. Clin Res Card. 2013; 102:661-9.

74. Cheung AW, White CW, Davis MK, Freed DH. Short-term mechanical circulatory support for recovery from acute right ventricular failure: clinical outcomes. J Heart Lung Transplant. 2014;33:794-9.

75. Anderson MB, Goldstein J, Milano C, Morris LD, Kormos RL, Bhama J, et al. Benefits of a novel percutaneous ventricular assist device for right heart failure: the prospective Recover Right study of the Impella RP device. J Heart Lung Transplant. 2015;34:1549-60.

76. Mallidi HR, Anand J, Cohn WE. State of the art of mechanical circulatory support. Tex Heart Inst J. 2014;41:115-20.

77. Arabia FA, Moriguchi JD. Machines versus medication for biventricular heart failure: focus on the total artificial heart. Future Cardiol. 2014;10: 593-609.

78. Mehra MR, Park MH, Landzberg MJ, Lala A, Waxman B. Right heart failure: toward a common language. J Heart Lung Transplant. 2014;33:123-6.

79. Lampert BC, Teuteberg JJ. Right ventricular failure after left ventricular assist devices. J Heart Lung Transplant. 2015;34:1123-30.
80. Hsu PL, Parker J, Egger C, Autschbach R, Schmitz-Rode T, Steinseifer U. Mechanical circulatory support for right heart failure: current technology and future outlook. Artific Organs. 2012;36:332-47.

81. Kato TS, Farr M, Schulze PC, Maurer M, Shahzad K, Iwata S, et al. Usefulness of two-dimensional echocardiographic parameters of left side of the heart to predict right ventricular failure after left ventricular assist device implantation. Am J Cardiol. 2012;109:246-51.

82. Frea S, Bovolo V, Bergerone S, D’Ascenzo F, Antolini M, Capriolo M, et al. Echocardiographic evaluation of right ventricular stroke work index in advanced heart failure: a new index? J Card Fail. 2012;18:886-93.

83. Potapov EV, Krabatsch T, Ventura HO, Hetzer R. Advances in mechanical circulatory support: year in review. J Heart Lung Transplant. 2011;30: 487-93.

84. Drews T, Krabatsch, Huebler M, Hetzer R. Paracorporeal biventricular mechanical support for more than 4 years. J Heart Lung Transplant. 2010;29:698-9.

85. Levin AP, Fried J, Wever-Oinzon O, Garan AR, Takeda K, Takayama H, et al. Bridging to transplant with fully implantable biventricular assist devices vs. total artificial heart implantation in patients with advanced biventricular failure. $J$ Heart Lung Transplant. 2015;34(4 Suppl):S152.

86. Takeda K, Naka Y, Yang J, Uriel N, Colombo PC, Jorde U, et al. Outcome of unplanned right ventricular assist device support for severe right heart failure after implantable left ventricular assist device insertion. J Heart Lung Transplant. 2014;33:141-8.

87. Kormos RL. The right heart failure dilemma in the era of left ventricular assist devices. J Heart Lung Transplant. 2014;33:134-5.

88. Dandel M, Krabatsch T, Falk V. Left ventricular vs. biventricular mechanical support: decision making and strategies for avoidance of right heart failure after left ventricular assist device implantation. Int J Cardiol. 2015;198:241-50.

89. Robertson JO, Naftel DC, Myers SL, Prasad S, Mertz GD, Itoh A, et al. Concomitant aortic valve procedures in patients undergoing implantation of continuous-flow left ventricular assist devices: an INTERMACS database analysis. J Heart Lung Transplant. 2015;34:797-805.

90. Milano C, Pagani FD, Slaughter MS, Pham DT, Hathaway DR, Jaoski MV, et al. Clinical outcomes after implantation of a centrifugal flow left ventricular assist device and concurrent cardiac valve procedures. Circulation. 2014;130(11 Suppl 1):S3-11.

91. Mallidi HR, Anand J, Singh SK. Long-term mechanical circulatory support: a new disease state? J Thorac Cardiovasc Surg. 2015;150:e13-4.

92. Wang TS, Hernandez AF, Felker GM, Milano CA, Rogers JG, Patel CB Valvular heart disease in patients supported with left ventricular assist devices. Circ Heart Fail. 2014;7:215-22.

93. John R, Naka Y, Park SJ, Sai-Sudhaker C, Salerno C, Sundaeswaran KS, et al. Impact of concurrent surgical valve procedures in patients receiving continuous flow devices. J Thorac Cardiovasc Surg. 2014;147:581-9.

94. Toda K, Fujita T, Domae K, Shimahara Y, Kobayash J, Nakatani T. Late aortic insufficiency related to poor prognosis during left ventricular assist device support. Ann Thorac Surg. 2011;92:929-34.

95. Schechter MA, Joseph JT, Krishnamoorthy A, Finet JE, Ganapathi AM, Lodge AJ, et al. Efficacy and durability of central oversewing or treatment of aortic insufficiency in patients with continuous-flow left ventricular assist devices. J Heart Lung Transplant. 2014;33:937-42.

96. Taghavi S, Hamad E, Wilson L, Clark R, Jayarajan SN, Uriel N, et al. Mitra valve repair at the time of continuous-flow left ventricular assist device implantation confers meaningful decrement in pulmonary vascular resistance. ASAIO J. 2013;59:469-73

97. Kirklin JK, Naftel DC, Pagani FD, Kormos RL, Myers S, Acker MA, et al. Pump thrombosis in the Thoratec HeartMate II device: an update analysis of the INTERMACS Registry. J Heart Lung Transplant. 2015;34:1515-26.

98. Adamson RM, Mangi AA, Kormos RL, Farrar OJ, Dembitsky WP. Principles of Heart Mate II implantation to avoid pump malposition and migration. J Card Surg. 2015;30:296-9.

99. Singh A, Russo MJ, Valeroso TB, Anderson AS, Allen S, Rich JD, et al. Modified Heart Mate II driveline externalization technique significantly decreases incidence of infection and improves long-term survival. ASAIO J. 2014;60: 613-6.

100. Schibilsky D, Benk C, Hailer C, Berchtold-Herz M, Siepe M, Beyersdorf F, et al. Double tunnel technique for the LVAD driveline: improved management regarding driveline infections. J Artif Organs. 2012;15:44-8.

101. Cheung A, Lamarche Y, Kan A, Munt B, Doyle A, Bashir J, et al. Off-pump implantation of the HeartWare HVAD left ventricular assist device through minimally invasive incisions. Ann Thorac Surg. 2011;91:1294-6. 
102. Schmitto JD, Molitoris U, Haverich A, Strueber M. Implantation of a centrifugal pump as a left ventricular assist device through a novel, minimized approach: upper hemisternotomy combined with anterolateral thoracotomy. $J$ Heart Lung Transplant. 2012;143:511-3.

103. Sileshi B, Haglund NA, Davis ME, Tricarico NM, Stulak JM, Khalpeny Z, et al. In-hospital outcomes of a minimally invasive off-pump left thoracotomy approach using a centrifugal continuous-flow left ventricular assist device. $J$ Heart Lung Transplant. 2015;34:10712.

104. Suarez J, Patel CB, Felker GM, Becker R, Hernandez AF, Rogers JG. Mechanisms of bleeding and approach to patients with axial-flow left ventricular assist devices. Circ Heart Fail. 2011;4:779-84.

105. Slaughter MS, Rogers JG, Milano CA, Russell SD, Conte JV, Feldman D, et al Advanced heart failure treated with continuous-flow left ventricular assist device. N Engl J Med. 2009;361:2241-51.

106. Pagani FD, Miller LW, Russell SD, Aaronson KD, John R, Boyle AJ, et al. Extended mechanical circulatory support with a continuous-flow rotary left ventricular assist device. J Am Coll $\mathrm{Ca}$ diol. 2009;54:312-21.

107. Slaughter MS, Pagani FD, Rogers JG, Miller LW, Sun B, Russell SD, et al. Clinical management of continuous-flow left ventricular assist devices in advanced heart failure. J Heart Lung Transplant. 2010;29:S1-39.

108. Feldman D, Pamboukian SV, Teuteberg JJ, Birks E, Lietz K, Moore SA, et al. The 2013 International Society for Heart and Lung Transplantation guidelines for mechanical circulatory support: executive summary. J Heart Lung Transplant. 2013;32:157-87.

109. Bhaskar B, Dulhunty J, Mullany DV, Fraser JF. Impact of blood product transfusion on short and long-term survival after cardiac surgery: more evidence. Ann Thorac Surg. 2012;94:460-7.

110. Schaffer JM, Arnaoutakis GJ, Allen JG, Weiss ES, Patel ND, Russell SD, et al Bleeding complications and blood product utilization with left ventricular assist device implantation. Ann Thorac Surg. 2011;91:740-9.

111. Fung YL, Silliman CC. The role of neutrophils in the pathogenesis of transfusion-related acute lung injury. Transfus Med Rev. 2009;23:266-83.

112. Dodd RY. Emerging pathogens in transfusion medicine. Clin Lab Med. 2010;30: 499-509.

113. Allen SJ, Sidebotham D. Post-operative care and complications after ventricular assist device implantation. Best Pract Res Clin Anaesthesiol. 2012;26:231-46.

114. Despotis G, Avidan M, Eby C. Prediction and management of bleeding in cardiac surgery. J Throm Haemost. 2009;7(Suppl 1):111-7.

115. Levy JH, Sniecinski RM. Prohemostatic treatment in cardiac surgery. Semin Thromb Hemost. 2012;38:237-43.

116. Shapira OM, Aldea GS, Lazar HL, Shemin RJ. Reduction of allogeneic blood transfusions after open heart operations by lowering cardiopulmonary bypass prime volume. Ann Thorac Surg. 1998;65:724-30.

117. Rosengart TK, DeBois W, O'Hara M, Helm R, Gomez M, Lang SJ, et al. Retrograde autologous priming for cardiopulmonary bypass: a safe and effective means of decreasing hemodilution and transfusion requirements. J Thorac Cardiovasc Surg. 1998;115:438-9.

118. Maltais S, David ME, Haglund N. Minimally invasive and alternative approaches for long-term LVAD placement: the Vanderbilt strategy. Ann Cardiothorac Surg. 2014;3:563-9.

119. Anyanwu AC. Technique for less invasive implantation of HeartMate II left ventricular assist device without median sternotomy. Semin Thorac Cardiovasc Surg. 2011;233:241-4

120. Gregoric ID, La Francesca S, Myers T, Cohn W, Loyalka P, Kar B, et al. A less invasive approach to axial flow pump insertion. J Heart Lung Transplant. 2008; 27:423-6.

121. Stulak JM, Romans T, Cowger J, Romano MA, Haft JW, Aaronson KD, et al. Delayed sternal closure does not increase late infection risk in patients undergoing left ventricular assist device implantation. J Heart Lung Transplant. 2012; 31:1115-9.

122. Hardy JF. Practice guidelines for perioperative blood management an updated report by the American Society of Anesthesiologists task force on perioperative blood management. Anesthesiology. 2015;122:241-75.

123. National Institutes of Health Consensus Conference. Fresh-frozen plasma. Indications and risks. JAMA. 1985;253:551-3.

124. Simon TL, Akl BF, Murphy W. Controlled trial of routine administration of platelet concentrates in cardiopulmonary bypass surgery. Ann Thorac Surg. 1984:37:359-64.

125. Despotis GJ, Santoro SA, Spitznagel E, Kater KM, Barnes P, Cox JL, et al. Onsite prothrombin time activated partial thrombo-plastin time, and platelet count.
A comparison between whole blood and laboratory assays with coagulation factor analysis in patients presenting for cardiac surgery. Anesthesiology. 1994;80 $338-51$.

126. Bruckner BA, Jacob LP, Walkes JC, Habib O, Reardon MJ, Loebe M, et al. Clinical experience with recombinant factor vii use in patients with left ventricular assist devices. J Heart Lung Transplant. 2008;27:S93.

127. O'Connell KA, Wood JJ, Wise RP, Lozier JN, Braun MM. Thromboembolic adverse events after use of recombinant human coagulation factor VIla. JAMA. 2006;295:293-8.

128. Gill R, Hebertson M, Vuylsteke A, Olsen PS, von Heymann C, Mythen M, et al. Safety and efficacy of recombinant activated factor VII: a randomized placebocontrolled trial in the setting of bleeding after cardiac surgery. Circulation. 2009; 120:21-7.

129. Levi M, Levy JH, Andersen HF, Truloff D. Safety of recombinant activated fac tor VII in randomized clinical trials. N Engl J Med. 2010;363:1791-800.

130. Bradford CD, Stahovich MJ, Dembitsky WP, Adamson RM, Engelbert JJ, Perreiter AS. Safety of prothombin complex concentrate to control excess bleeding during continuous flow LVAD insertion. ASAIO J. 2015;61:509-13.

131. Abbott. Cardiovascular home. Available at: http://www.thoratec.com/medical professionals/resource-library/ifus-manuals/heartmate-ll-lvad.aspx.

132. HeartWare Ventricular Assist System instructions for use. Available at: http:// www.heartware.com/sites/default/files/uploads/docs/ifu00001_rev_15.pdf. Accessed December 23, 2019.

133. Adatya S, Uriel N, Yarmohammadi H, Holley CT, Feng A, Roy SS, et al. Antifactor $\mathrm{Xa}$ and activated partial thromboplastin time measurements for heparin monitoring in mechanical circulatory support. JACC Heart Fail. 2015;3:314-22.

134. Stehlik J, Johnson SA, Selzman CH. Gold standard in anticoagulation assessment of left ventricular assist device patients? JACC Heart Fail. 2015;3:323-6.

135. Yeh CH, Hogg K, Weitz JI. Overview of the new oral anticoagulants. Arterios cler Thromb Vasc Biol. 2015;35:1056-65.

136. Morales DL, Gregg D, Helman DN, Williams MR, Naka Y, Landry DW, et al. Arginine vasopressin in the treatment of 50 patients with postcardiotomy vasodilatory shock. Ann Thorac Surg. 2000;69:102-6.

137. Hayward CS, Salamonsen R, Keogh AM, Woodard J, Ayre P, Prichard R, et al. Effect of alteration in pump speed on pump output and left ventricular filling with continuous-flow left ventricular assist device. ASAIO J 2011;57:495-500.

138. Kitada S, Kato TS, Thomas SS, Conwell SD, Russo C, DiTullio MR, et al. Preoperative echocardiographic features associated with persistent mitral regurgitation after left ventricular assist device implantation. J Heart Lung Transplant. 2013;32:897-904.

139. Jorde UP, Uriel N, Nahumi N, Bejar D, Gonzalez-Costello J, Thomas SS, et al. Prevalence, significance, and management of aortic insufficiency in continuous flow left ventricular assist device recipients. Circ Heart Fail. 2014;7:310-9.

140. Cowger J, Pagani FD, Haft JW, Romano MA, Aaronson KD, Kolias TJ. The development of aortic insufficiency in LVAD supported patients. Circ Heart Fail. 2010;3:668-74.

141. Cowger J, Rao V, Massey T, Sun B, May-Newman K, Jorde U, et al. Comprehensive review and suggested strategies for the detection and management of aortic insufficiency in patients with a continuous-flow left ventricular assist device. J Heart Lung Transplant. 2015;34:149-57.

142. Heilmann C, Geisen U, Beyersdorf F, Nakamura L, Benk C, Berchtold-Herz M, et al. Acquired von Willebrand syndrome in patients with ventricular assist device or total artificial heart. Thromb Haemost. 2010;104:962-7.

143. Heilmann C, Geisen U, Beyersdorf F, Nakamura L, Benk C, Trummer G, et al. Acquired von Willebrand syndrome in patients with extracorporeal life support (ECLS). Intensive Care Med. 2012;38:62-8.

144. Uriel N, Pak SW, Jorde UP, Jude B, Susen S, Vincentelli A, et al. Acquired von Willebrand syndrome after continuous-flow mechanical device support contributes to a high prevalence of bleeding during long-term support and at the time of transplantation. J Heart Lung Transplant. 2010;56:1207-13.

145. Morrison KA, Jorde UP, Garan AR, Takayama H, Naka Y, Uriel N. Acquired von Willebrand disease during CentriMag support is associated with high prevalence of bleeding during support and after transition to heart replacement therapy. ASAIO J. 2014;60:241-2.

146. Aggarwal A, Pant R, Kumar S, Sharma P, Gallagher C, Tatooles AJ, et al. Incidence and management of gastrointestinal bleeding with continuous flow assist devices. Ann Thorac Surg. 2012;93:1534-40.

147. Wever-Pinzon O, Selzman CH, Drakos SG, Saidi A, Stoddard GJ, Gilbert EM, et al. Pulsatility and the risk of nonsurgical bleeding in patients supported with 
the continuous-flow left ventricular assist device HeartMate II. Circ Heart Fail. 2013;6:517-26.

148. Uriel N, Levin AP, Sayer GT, Mody KP, Thomas SS, Adatya S, et al. Left ventricular decompression during speed optimization ramps in patients supported by continuous-flow left ventricular assist devices: device-specific performance characteristics and impact on diagnostic algorithms. J Card Fail. 2015;21:785-91.

149. Park SJ, Milano CA, Tatooles AJ, Rogers JG, Adamson RM, Steidley DE, et al. Outcomes in advanced heart failure patients with left ventricular assist devices for destination therapy. Circ Heart Fail. 2012;5:241-8.

150. Brisco MA, Coca SG, Chen J, Owens AT, McCauley BD, Kimmel SE, et al. The blood urea nitrogen to creatinine ratio identifies a high risk but potentially reversible form of renal dysfunction in patients with decompensated heart failure. Circ Heart Fail. 2013;6:223-9.

151. Patel AM, Adeseun GA, Ahmed I, Mitter N, Rame JE, Rudnick MR. Renal failure in patients with left ventricular assist devices. Clin J Am Soc Nephrol. 2013; 8:484-96.

152. Mehra MR, Stewart GC, Uber PA. The vexing problem of thrombosis in longterm mechanical circulatory support. J Heart Lung Transplant. 2014;33:1-11.

153. Starling RC, Moazami N, Silvestry SC, Ewald G, Rogers JG, Milano CA, et al. Unexpected abrupt increase in left ventricular assist device thrombosis. $N$ Engl J Med. 2014;370:33-40.

154. Shah P, Mehta VM, Cowger JA, Aaronson KD, Pagani FD. Diagnosis of hemolysis and device thrombosis with lactate dehydrogenase during left ventricular assist device support. J Heart Lung Transplant. 2014;33:102-4.

155. Akin S, Soliman OL, Constantinescu AA, Akca F, Birim O, van Domburg RT, et al. Haemolysis as a first sign of thromboembolic event and acute pump thrombosis in patients with the continuous-flow left ventricular assist device HeartMate II. Neth Heart J. 2016;24:134-42.

156. Cowger JA, Romano MA, Shah P, Shah N, Mehta V, Haft JW, et al. Hemolysis: a harbinger of adverse outcome after left ventricular assist device implant. $J$ Heart Lung Transplant. 2014;33:35-43.

157. Vivo RP, Kassi M, Estep JD, Bhimaraj A, Trachetenberg BH, Orrego CM, et al. MDCT assessment of mechanical circulatory device complications. JACC Cardiovasc Imaging. 2015;8:100-2.

158. Goldstein DJ, John R, Salerno C, Silvestry S, Moazami N, Horstmanshof D, et al. Algorithm for the diagnosis and management of suspected pump thrombus. J Heart Lung Transplant. 2013;32:667-70.

159. Fine NM, Topilsky Y, Oh JK, Hasin T, Kushwaha SS, Daly RC, et al. Role of echocardiography in patients with intravascular hemolysis due to suspected continuous-flow LVAD thrombosis. JACC Cardiovasc Imaging. 2013;6: $1129-40$.

160. Pamboukian SV, Tallaj JA, Brown RN, Holman WL, Blood M, George JF, et al. Improvement in 2-year survival for ventricular assist device patients after implementation of an intensive surveillance protocol. J Heart Lung Transplant. 2011;30:879-87.

161. Levin AP, Uriel N, Takayama H, Mody KP, Ota T, Yuzefpolskaya M, et al. Device exchange in HeartMate II recipients: long-term outcomes and risk of thrombosis recurrence. ASAIO J. 2015;61:144-9.

162. Najjar SS, Slaughter MS, Pagani FD, Starling RC, McGee EC, Eckman P, et al. An analysis of pump thrombus events in patients in the HeartWare ADVANCE bridge to transplant and continued access protocol trial. J Heart Lung Transplant. 2014;33:23-34.

163. Mozaffarian D, Benjamin EJ, Go AS, Arnett DK, Blaha MJ, Cushman M, et al, Heart disease and stroke statistics-2015 update: a report from the American Heart Association. Circulation. 2016;133:e38-360.

164. Mehra MR, Goldstein DJ, Uriel N, Cleveland JC Jr, Yuzefpolskaya M, Salerno C, et al. Two-year outcomes with a magnetically levitated cardiac pump in heart failure. N Engl J Med. 2018;378:1386-95.

165. Blitz A. Pump thrombosis — a riddle wrapped in a mystery inside an enigma. Ann Cardiothorac Surg. 2014;3:450-71.

166. Sylvia LM, Ordway L, Pham DT, DeNofrio D, Kiernan M. Bivalirudin for treatment of LVAD thrombosis: a case series. ASAIO J. 2014;60:744-7.

167. Badiye A, Hernandez GA, Chaparro S. Argatroban as novel therapy for suspected thrombosis in patients with continuous-flow left ventricle assist device and hemolysis. ASAIO J. 2014;60:361-5.

168. Tellor BR, Smith JR, Prasad SM, Joseph SM, Silvestry SC. The use of eptifibatide for suspected pump thrombus or thrombosis in patients with left ventricular assist devices. J Heart Lung Transplant. 2014;33:94-101.

169. Kiernan MS, Pham DT, DeNofrio D, Kapur NK. Management of HeartWare left ventricular assist device thrombosis using intracavitary thrombolytics. J Thorac Cardiovasc Surg. 2011;142:712-4.
170. Ota T, Yerebakan H, Akashi H, Takayama H, Uriel N, Colombo PC, et al. Continuous-flow left ventricular assist device exchange: clinical outcomes. $J$ Heart Lung Transplant. 2014;33:65-70.

171. Raffa GM, D'ancona G, Sciacca S, Pietrosi A, Hernandez Baravoglia CM, Turissi M, et al. Systemic or endoventricular thrombolysis to treat HeartWare left ventricle assist device thrombosis: a clinical dilemma. Artif Organs. 2015;39:526-9.

172. Kirklin JK, Naftel DC, Pagani FD, Kormos RL, Stevenson LW, Blume ED, et al Seventh INTERMACS annual report: 15,000 patients and counting. J Heart Lung Transplant. 2015;34:1495-504.

173. Aissaoui N, Borgermann J, Gummert J, Morshuis M. HeartWare continuousflow ventricular assist device thrombosis: the Bad Oeynhausen experience. $J$ Thorac Cardiovasc Surg. 2012;143:e37-9.

174. Al-Quthami AH, Jumean M, Kociol R, Pham DT, Kiernan M, DeNofrio D. Eptifibatide for the treatment of HeartMate II left ventricular assist device thrombosis. Circ Heart Fail. 2012;5:e68-70.

175. Pappalardo F, Scandroglio AM, Potapov E, Stepanenko A, Maj G, Krabatsch T, et al. Argatroban anticoagulation for heparin induced thrombocytopenia in patients with ventricular assist devices. Minerva Anestesiol. 2012;78:330-5.

176. Barbieri A, Bertelli L, Sangiorgi GM. Novel application of angiojet rheolytic thrombectomy for massive thrombosis of the native aortic valve and Jarvick 2000 ventricular assist device in a patient with end-stage heart failure. Cath Cardiovasc Interv. 2011;78:958-61.

177. Rothenburger M, Wilhelm MJ, Hammel D, Schmidt C, Tjan TD, Bocker D et al. Treatment of thrombus formation associated with the MicroMed DeBakey VAD using recombinant tissue plasminogen activator. Circulation. 2002;106(12 Suppl 1):I189-92.

178. Ninios V, Visouli A, Pitsis A. Images in cardiovascular medicine. Repeated successful thrombolysis of a Jarvik 2000 left ventricular assist device in a patient with noncompaction cardiomyopathy. Circulation. 2010;121:e13-4.

179. Hayes H, Dembo L, Larbalestier R, O’Driscoll G. Successful treatment of ventricular assist device associated ventricular thrombus with systemic tenecteplase. Heart Lung Circ. 2008;17:253-5.

180. Tang GH, Kim MC, Pinney SP, Anyanwu AC. Failed repeated thrombolysis requiring left ventricular assist device pump exchange. Catheter Cardiovasc Interv. 2013;81:1072-4.

181. Agarwal R, Raina A, Lasorda DM, Moraca RJ, Bailey SH, Kanwar M, et al. Successful treatment of acute left ventricular assist device thrombosis and cardiogenic shock with intraventricular thrombolysis and a tandem heart. ASAIO J. 2015;61:98-101.

182. Webber BT, Panos AL, Rodriguez-Blanco YF. Intravenous thrombolytic therapy for patients with ventricular assist device thrombosis: an attempt to avoid reoperation. Ann Card Anaesth. 2016;19:192-6.

183. Upshaw JN, Kiernan MS, Morine KJ, Kapur NK, DeNofrio D. Incidence, management, and outcome of suspected continuous-flow left ventricular assist device thrombosis. ASAIO J. 2016;62:33-9.

184. Jahanyar J, Noon GP, Koerner MM, Youker KA, Malaisrie SC, Ngo UQ, et al Recurrent device thrombi during mechanical circulatory support with an axialflow pump is a treatable condition and does not preclude successful long-term support. J Heart Lung Transplant. 2007;26:200-3.

185. Oezpeker C, Zittermann A, Ensminger S, Kizner L, Koster A, Sayin A, et al Systemic thrombolysis versus device exchange for pump thrombosis management: a single-center experience. ASAIO J. 2016;62:246-51.

186. Schlendorf K, Patel CB, Gehrig T, Kiefer TL, Felker GM, Hernandez AF, et al Thrombolytic therapy for thrombosis of continuous flow ventricular assist devices. J Card Fail. 2014;20:91-7.

187. Russo C, De Biase AM, Bruschi G, Agati S, Vitali E. Successful intraventricular thrombolysis during ventricular assist device support. Ann Thorac Surg. 2002; 73:1628-9.

188. Tschirkov A, Nikolov D, Tasheva I, Papantchev V. Successful fibrinolysis after acute left ventricular assist device thrombosis. J Heart Lung Transplant. 2007; 26:553-5.

189. Delgado R, Frazier OH, Myers TJ, Gregoric ID, Robertson K, Shah NA, et al. Direct thrombolytic therapy for intraventricular thrombosis in patients with the Jarvik 2000 left ventricular assist device. J Heart Lung Transplant. 2005;24:231-3.

190. Kamouh A, John R, Eckman P. Successful treatment of early thrombosis of HeartWare left ventricular assist device with intraventricular thrombolytics. Ann Thorac Surg. 2012;94:281-3.

191. Thenappan T, Anderson AS, Jeevanadham V, Rich JD, Shah AP. Treatment of left ventricular assist device thrombosis with extended catheter-directed intraventricular thrombolytic therapy. Circ Heart Fail. 2013;6:27-9. 
192. Jabbar AA, Yau R, Frazier OH, Delgado R III. Direct thrombolytic therapy for thrombosis of a centrifugal flow left ventricular assist device. ASAIO J. 2013; 59:530-2.

193. Moazami N, Milano CA, John R, Sun B, Adamson RM, Pagani FD, et al. HeartMate II Investigators. Pump replacement for left ventricular assist device failure can be done safely and is associated with low mortality. Ann Thorac Surg. 2013; 95:500-5.

194. Boyle AJ, Russell SD, Teuteberg JJ, Slaughter MS, Moazami N, Pagani FD, et al. Low thromboembolism and pump thrombosis with the HeartMate II left ventricular assist device: analysis of outpatient anti-coagulation. J Heart Lung Transplant. 2009;28:881-7.

195. Miller LW, Pagani FD, Russell SD, John R, Boyle AJ, Aaronson KD, et al. Use of a continuous-flow device in patients awaiting heart transplantation. $N$ Engl $J$ Med. 2007;357:885-96.

196. Hannan MM, Husain S, Mattner F, Danziger-Isakov L, Drew RJ, Corey GR, et al. Working formulation for the standardization of definitions of infections in patients using ventricular assist devices. J Heart Lung Transplant. 2011; 30:375-84.

197. Kusne S, Mooney M, Danziger-Isakov L, Kaan A, Lund LH, Lyster H, et al. An ISHLT consensus document for prevention and management strategies for mechanical circulatory support infection. J Heart Lung Transplant. 2017;36: 1137-53.

198. Cimochowski GE, Harostock MD, Brown R, Bernardi M, Alonzo N, Coyle K. Intranasal mupirocin reduces sternal wound infection after open heart surgery in diabetics and nondiabetics. Ann Thorac Surg. 2001;71:1572-9.

199. Hannan MM, Xie R, Kusne S, Merry C, Grossi P, Stosor V, et al. Antimicrobial surgical prophylaxis in MCS implant surgery and surgical site infection, IMACS January 2013 to December 2015. J Heart Lung Transplant. 2017;36:S40.

200. Holman WL. Microbiology of infection in mechanical circulatory support. Int J Artif Organs. 2007;30:764-70.

201. Fleissner F, Avsar M, Malehsa D, Strueber M, Haverich A, Schmitto JD. Reduction of driveline infections through doubled driveline tunneling of left ventricular assist devices. Artif Organs. 2013;37:102-7.

202. Arrecubieta C, Toba FA, von Bayern M, Akashi H, Deng MC, Naka Y, et al. SdrF, a Staphylococcus epidermidis surface protein, contributes to the initiation of ventricular assist device driveline-related infections. PLoS Pathog. 2009;5: e1000411.

203. Chinn R, Dembitsky W, Eaton L, Chillcott S, Stahovich M, Rasmusson B, et al. Multicenter experience: prevention and management of left ventricular assist device infections. ASAIO J. 2005;51:461-70.

204. Garatti A, Giuseppe B, Russo CF, Marco O, Ettore V. Drive-line exit-site infection in a patient with axial-flow pump support: successful management using vacuum-assisted therapy. J Heart Lung Transplant. 2007;26:956-9.

205. Baradarian S, Stahovich M, Krause S, Adamson R, Dembitsky W. Case series: clinical management of persistent mechanical assist device driveline drainage using vacuum-assisted closure therapy. ASAIO J. 2006;52:354-6.

206. Hozayen SM, Soliman AM, Eckman PM. Comparison of two ventricular assist device dressing change protocols. J Heart Lung Transplant. 2012; $31: 108-9$

207. Jiritano F, Serraino GF, Rossi M, Dominijanni A, Brescia A, Renzulli A. Ventricular assist device driveline infection: treatment with platelet-rich plasma. Ann Thorac Surg. 2013;96:e37-8.

208. Abicht T, Gordon R, Meehan K, Stosor V, McCarthy P, McGee E Jr. Complex HeartMate II infection treated with pump exchange to HeartWare HVAD ASAIO J. 2013;59:188-92.

209. Anand J, Singh SK, Hernández R, Parnis SM, Civitello AB, Cohn WE, et al. Continuous-flow ventricular assist device exchange is safe and effective in prolonging support time in patients with end-stage heart failure. J Thorac Cardiovasc Surg. 2015;149:267-78.

210. Levy DT, Guo Y, Simkins J, Puius YA, Muggia VA, Goldstein DJ, et al. Left ventricular assist device exchange for persistent infection: a case series and review of the literature. Transpl Infect Dis. 2014;16:453-60.

211. Simon MA, Kormos RL, Murali S, Nair P, Heffernan M, Gorcsan J, et al. Myocardial recovery using ventricular assist devices: prevalence, clinical characteristics, and outcomes. Circulation. 2005;112(9 Suppl):I32-6.

212. Birks EJ, George RS, Hedger M, Bahrami T, Wilton P, Bowles CT, et al. Reversal of severe heart failure with a continuous-flow left ventricular assist de- vice and pharmacological therapy: a prospective study. Circulation. 2011;123: 381-90.

213. Birks EJ, Tansley PD, Hardy J, George RS, Bowles CT, Burke M. Left ventric ular assist device and drug therapy for the reversal of heart failure. $N$ Engl J Med. 2006;355:1873-84.

214. Dandel M, Knosalla C, Hetzer R. Contribution of ventricular assist devices to the recovery of failing hearts: a heview and the Berlin Heart Center Experience. Eur J Heart Fail. 2014;16:248-63.

215. Dandel M, Weng Y, Siniawski H, Potapov E, Krabatsch T, Lehmkuhl HB, et al. Pre-explant stability of unloading-promoted cardiac improvement predicts outcome after weaning from ventricular assist devices. Circulation. 2012; 126(11 Suppl 1):S9-19.

216. George RS, Yacoub MH, Bowles CT, Hipkin M, Rogers P, Hallas C, et al. Quality of life after removal of left ventricular assist device for myocardial recovery. J Heart Lung Transplant. 2008;27:165-72.

217. Birks EJ, Drakos S, Selzman C, Starling R, Cunningham C, Slaughter M, et al Remission from stage D heart failure (RESTAGE-HF): early results from a prospective multi-center study of myocardial recovery. J Heart Lung Transplant. 2015;34:S40-1.

218. Drakos SG, Wever-Pinzon O, Selzman CH, Gilbert EM, Alharethi R, Reid BB, et al. Magnitude and time course of changes induced by continuous-flow left ventricular assist device unloading in chronic heart failure: insights into cardiac recovery. J Heart Lung Transplant. 2013;61: 1985-94.

219. Patel SR, Saeed O, Murthy S, Bhatia V, Shin JJ, Wang D, et al. Combining neurohormonal blockade with continuous-flow left ventricular assist device support for myocardial recovery: a single-arm prospective study. J Heart Lung Transplant. 2013;32:305-12.

220. Catino AB, Al-Sari M, McCubrey R, Wever-Pinzon J, Selzman C, Wright S, et al. What is the role of standard heart failure drug therapy in the context of VAD-induced unloading of the failing human heart? J Heart Lung Transplant. 2015;34:S64.

221. Birks EJ, Drakos SG, Lowes BD, Patel SR, Selzman C, Slaughter MS, et al. Outcome and primary endpoint results from a prospective multicenter study of myocardial recovery using LVADs: remission from Stage D Heart Failure (RESTAGE-HF). J Heart Lung Transplant. 2018;37: S142.

222. Uriel N, Kim G, Burkhoff D. Myocardial recovery after LVAD implantation. $J$ Am Coll Cardiol. 2017;70:355-7.

223. Reich HJ, Czer LS, Ramzy D, Arabia F, Moriguchi J, Ascheim DD, et al. Combining stem cell therapy for advanced heart failure and ventricular assist devices: a review. ASAIO J. 2018;64:80-7.

224. Ascheim DD, Gelijns AC, Goldstein D, Moye LA, Smedira N, Lee S, et al. Mesenchymal precursor cells as adjunctive therapy in recipients of contemporary left ventricular assist devices: clinical perspective. Circulation. 2014;129: 2287-96.

225. Rao V, Slater JP, Edwards NM, Naka Y, Oz MC. Surgical management of valvular disease in patients requiring left ventricular assist device support. Ann Thorac Surg. 2001;71:1448-53.

226. Selzman CH, Madden JL, Healy AH, McKellar SH, Koliopoulou A, Stehlik J, et al. Bridge to removal: a paradigm shift for left ventricular assist device therapy. Ann Thorac Surg. 2015;99:360-7.

227. Birks EJ, George RS, Firouzi A, Wright G, Bahrami T, Yacoub MH, et al. Long term outcomes of patients bridged to recovery versus patients bridged to transplantation. J Thorac Cardiovasc Surg. 2012;144:190-6.

228. Frazier OH, Baldwin AC, Demirozu ZT, Segura AM, Hernandez R, Taegtmeyer $\mathrm{H}$, et al. Ventricular reconditioning and pump explantation in patients supported by continuous-flow left ventricular assist devices. J Heart Lung Transplant. 2015;34:766-72.

229. Formica P, Murthy S, Edwards P, Goldstein D, Maybaum S. A structured 3-step approach to evaluate cardiac recovery with continuous flow circulatory support. J Heart Lung Transplant. 2010;29:1440-2.

Key Words: mechanical circulatory support, left ventricular assist device, continuous flow pumps, advanced heart failure 
APPENDIX 1. Relationships with industry and other relevant entities for guideline editors, contributing authors, and reviewers

\begin{tabular}{|c|c|c|c|c|c|c|c|}
\hline Contributor & Role & Institution & Grants & Personal fees & Nonfinancial support & Other & Comments \\
\hline James K. Kirklin & Editor & $\begin{array}{l}\text { University of Alabama at } \\
\text { Birmingham }\end{array}$ & None & Xeltis & None & $\begin{array}{l}\text { Society of Thoracic } \\
\text { Surgeons }\end{array}$ & $\begin{array}{l}\text { Xeltis: Chair of DSMB for } \\
\text { valved conduit trial (1- } \\
\text { time fee) } \\
\text { Society of Thoracic Surgeons: } \\
\text { Director, INTERMACS } \\
\text { MCS Registry Data Center } \\
\text { (partial salary paid to } \\
\text { institution) }\end{array}$ \\
\hline Francis D. Pagani & Editor & University of Michigan & None & None & None & FineHeart, Inc & None \\
\hline Daniel J. Goldstein & Editor & $\begin{array}{l}\text { Montefiore Medical Center/ } \\
\text { Albert Einstein College of } \\
\text { Medicine }\end{array}$ & None & Abbott & None & None & $\begin{array}{l}\text { Abbott: Surgical proctor and } \\
\text { educator }\end{array}$ \\
\hline Ranjit John & Editor & University of Minnesota & $\begin{array}{l}\text { Abbott, } \\
\text { Medtronic }\end{array}$ & $\begin{array}{l}\text { Abbott, } \\
\text { Medtronic }\end{array}$ & None & None & $\begin{array}{l}\text { Abbott: Consulting }(<\$ 5000) \\
\text { Medtronic: Consulting } \\
\quad(<\$ 5000)\end{array}$ \\
\hline Joseph G. Rogers & Editor & $\begin{array}{l}\text { Duke University School of } \\
\text { Medicine }\end{array}$ & None & None & None & None & None \\
\hline Pavan Atluri & Contributing author & University of Pennsylvania & None & $\begin{array}{l}\text { Medtronic, } \\
\text { Edwards Lifesciences }\end{array}$ & None & None & $\begin{array}{l}\text { Medtronic: Surgical Advisory } \\
\text { Board }(<\$ 5000) \\
\text { Edwards Lifesciences: Course } \\
\quad \text { director, mitral valve } \\
\quad(<\$ 5000)\end{array}$ \\
\hline Francisco A. Arabia & Contributing author & $\begin{array}{c}\text { Banner Health University of } \\
\text { Arizona Medical Center }\end{array}$ & None & $\begin{array}{l}\text { SynCardia Systems, } \\
\text { Medtronic }\end{array}$ & $\begin{array}{l}\text { Carmat, } \\
\text { BiVacor }\end{array}$ & None & $\begin{array}{l}\text { SynCardia Systems: } \\
\quad \text { Consultant } \\
\text { Medtronic: Consultant } \\
\text { Carmat: Consultant } \\
\text { BiVacor: Consultant }\end{array}$ \\
\hline Anson Cheung & Contributing author & $\begin{array}{l}\text { University of British } \\
\text { Columbia }\end{array}$ & None & $\begin{array}{l}\text { Medtronic, } \\
\text { Abbott Vascular }\end{array}$ & None & None & $\begin{array}{l}\text { Medtronic: Consultant } \\
\text { Abbott Vascular: Consultant }\end{array}$ \\
\hline William Holman & Contributing author & $\begin{array}{l}\text { University of Alabama at } \\
\text { Birmingham }\end{array}$ & None & None & None & Abbott & $\begin{array}{c}\text { Abbott: DSMB service } \\
\text { HeartMate } 3 \text { study }\end{array}$ \\
\hline Charles Hoopes & Contributing author & $\begin{array}{l}\text { University of Alabama at } \\
\text { Birmingham }\end{array}$ & None & None & None & None & None \\
\hline Valuvan Jeevanandam & Contributing author & University of Chicago & None & $\begin{array}{l}\text { Thoratec, } \\
\text { Abbott }\end{array}$ & None & None & $\begin{array}{l}\text { Thoratec: Advisor } \\
\text { Abbott: Advisor }\end{array}$ \\
\hline Ulrich P. Jorde & Contributing author & $\begin{array}{l}\text { Montefiore Medical Center/ } \\
\text { Albert Einstein College of } \\
\text { Medicine }\end{array}$ & None & Abbott & None & Abbott & $\begin{array}{l}\text { Abbott: }<\$ 5000 \text { and travel } \\
\text { reimbursement }\end{array}$ \\
\hline Carmelo A. Milano & Contributing author & $\begin{array}{l}\text { Duke University School of } \\
\text { Medicine }\end{array}$ & None & Abbott & None & Syncardia & $\begin{array}{l}\text { Syncardia: Medical advisor } \\
\text { Abbott: Proctor/training }\end{array}$ \\
\hline Nader Moazami & Contributing author & $\begin{array}{l}\text { New York University } \\
\text { Langone Medical Center }\end{array}$ & None & None & None & None & None \\
\hline Yoshifumi Naka & Contributing author & $\begin{array}{l}\text { Columbia University College } \\
\text { of Physicians \& Surgeons }\end{array}$ & None & $\begin{array}{l}\text { Abbott, } \\
\text { Nipro Corp, } \\
\text { Zimmer Biomet, } \\
\text { CryoLife }\end{array}$ & None & None & $\begin{array}{l}\text { Abbott: Consultant (sum of } \\
\text { payment }<\$ 5000 / y \text { ) } \\
\text { Nipro Corp: Speaker (sum of } \\
\text { payment }<\$ 5000 / y \text { ) } \\
\text { Zimmer Biomet: Consultant } \\
\text { CryoLife: Consultant }\end{array}$ \\
\hline Ivan Netuka & Contributing author & $\begin{array}{l}\text { Institute for Clinical and } \\
\text { Experimental Medicine, } \\
\text { Prague, Czech Republic }\end{array}$ & $\begin{array}{l}\text { Abbott, } \\
\text { Carmat SA }\end{array}$ & $\begin{array}{l}\text { Abbott, } \\
\text { Carmat SA, } \\
\text { Evaheart Inc }\end{array}$ & $\begin{array}{l}\text { Abbott, } \\
\text { Carmat SA, } \\
\text { LeviticusCardio Ltd } \\
\text { Evaheart Inc. }\end{array}$ & LeviticusCardio Ltd & $\begin{array}{l}\text { Abbott: Research grant site PI } \\
\text { or overall PI, consultant } \\
\text { Carmat SA: research grant } \\
\text { site PI or overall PI, } \\
\text { consultant } \\
\text { LeviticusCardio Ltd: } \\
\text { Scientific/Medical } \\
\text { Advisory Board member, } \\
\text { corporate board member, } \\
\text { stock shareholder }\end{array}$ \\
\hline Salpy V. Pamboukian & Contributing author & $\begin{array}{l}\text { University of Alabama at } \\
\text { Birmingham }\end{array}$ & None & None & None & None & None \\
\hline
\end{tabular}


APPENDIX 1. Continued

\begin{tabular}{|c|c|c|c|c|c|c|c|}
\hline Contributor & Role & Institution & Grants & Personal fees & Nonfinancial support & Other & Comments \\
\hline Sean Pinney & Contributing author & Mount Sinai Hospital & None & $\begin{array}{l}\text { Abbott } \\
\text { CareDx } \\
\text { Medtronic } \\
\text { Procyrion }\end{array}$ & None & None & None \\
\hline Craig H. Selzman & Contributing author & $\begin{array}{l}\text { University of Utah School of } \\
\text { Medicine }\end{array}$ & None & None & None & None & None \\
\hline Scott Silvestry & Contributing author & $\begin{array}{l}\text { Florida Hospital Transplant } \\
\text { Institute }\end{array}$ & None & $\begin{array}{l}\text { Abbott, } \\
\text { Medtronic, } \\
\text { Syncardia }\end{array}$ & None & None & $\begin{array}{l}\text { Abbott: Consultant } \\
\text { Medtronic: Consultant } \\
\text { Syncardia: Consultant }\end{array}$ \\
\hline Mark Slaughter & Contributing author & University of Louisville & None & None & None & None & None \\
\hline John Stulak & Contributing author & $\begin{array}{l}\text { Mayo Clinic College of } \\
\text { Medicine and Science }\end{array}$ & None & None & None & None & None \\
\hline Jeff Teuteberg & Contributing author & Stanford University & None & $\begin{array}{l}\text { Abbott, } \\
\text { Medtronic, } \\
\text { Abiomed, } \\
\text { CareDx }\end{array}$ & None & None & $\begin{array}{l}\text { Abbott: HeartMate } 3 \text { Clinical } \\
\text { Events Committee } \\
\text { Medtronic: Advisory Board, } \\
\text { speaking } \\
\text { Abiomed: Advisory Board } \\
\text { CareDx: Advisory Board, } \\
\text { speaking }\end{array}$ \\
\hline Juliane Vierecke & Contributing author & $\begin{array}{l}\text { University of Cincinnati } \\
\text { College of Medicine }\end{array}$ & None & None & None & None & None \\
\hline Stephan Schueler & Reviewer & $\begin{array}{l}\text { Newcastle upon Tyne } \\
\text { Hospital Trust Freeman } \\
\text { Hospital, UK }\end{array}$ & None & Medtronic & None & None & $\begin{array}{l}\text { Medtronic: Proctor/consultant } \\
\text { for HVAD }\end{array}$ \\
\hline David A. D'Alessandro & Reviewer & $\begin{array}{l}\text { Massachusetts General } \\
\text { Hospital }\end{array}$ & None & None & None & None & None \\
\hline
\end{tabular}

$D S M B$, Data safety and monitoring board; $P I$, principal investigator. 